Anales de Geografía de la Universidad Complutense ISSN: 0211-9803

http://dx.doi.org/10.5209/rev_AGUC.2016.v36.n1.52716

\title{
Las actividades económicas y la organización funcional del territorio litoral de Asturias
}

\author{
Fermín Rodríguez Gutiérrez ${ }^{1}$ \\ Recibido: 3 de noviembre del 2015 / Enviado a evaluar: 23 de enero del 2016 / Aceptado: 3 de mayo del 2016
}

Resumen. El artículo tiene como finalidad la de aumentar el conocimiento del territorio litoral asturiano, mediante la utilización de una metodología descriptiva basada en el análisis funcional. Establece procedimientos de análisis y concluye con el diagnóstico de las actividades presentes en el territorio litoral indicativamente delimitado, para acercarse a la identificación de sus unidades territoriales componentes, consideradas como espacios motores o de integración dentro de la escala regional.

Palabras clave: Asturias; economía azul; análisis funcional; territorio litoral; diagnóstico territorial; espacios motores; espacios de integración.

\section{[en] The economic activities and functional organization of the Asturias coast}

\begin{abstract}
This paper proposes a methodology for analyze coastal territories focused on the functional analysis. It establishes analysis and diagnosis procedures for the activities of a coastal territory, and organizes its monitoring during time, allowing a consistent definition for the coastal territories as engines spaces or integrated spaces

Key words: Asturias; blue economy; functional analysis; coastal territory; territorial diagnosis; engines spaces; integrated spaces
\end{abstract}

\section{[fr] Les activitiés économiques et l'organisation fonctionnelle du territoire côtier des Asturies}

Résumé.L'article vise à accroître la connaissance du territoire côtier asturienne, en utilisant une méthodologie descriptive basée sur l'analyse fonctionnelle. Établit des procédures pour l'analyse et le diagnostic des activités présentes dans le territoire côtier délimité a titre indicatif, pour aborder l'identification de ses unités composantes, considérées comme unités territoriaux moteurs ou de l'intégration dans le espace régional

Mots clés : Asturias; économie bleue; Analyse fonctionnelle; territoire côtier; diagnostic territorial; espaces moteurs; espaces d'integration.

1 Departamento de Geografía y CeCodet. Universidad de Oviedo.

E-mail: farragut@uniovi.es 
Cómo citar. Rodríguez Gutiérrez, F. (2016): Las actividades económicas y la organización funcional del territorio litoral de Asturias. Anales de Geografía de la Universidad Complutense, 36(1), 109-147.

Sumario. 1. Introducción. 2. El área de estudio y la metodología. 3. El análisis de las actividades económicas y de los sectores de apoyo. 3.1. El sector primario marino. 3.1.1. El subsector pesquero. 3.1.2. El subsector de la acuicultura, recolección de algas y marisqueo. 3.2. El sector primario terrestre. 3.2.1. El subsector ganadero. 3.2.2. El subsector agrícola. 3.2.3. El sector industrial. 3.2.3.1. El subsector de la industria naval. 3.2.3.2. El suelo industrial. 3.2.4. El sector turístico. 3.2.5. El sector de la investigación e innovación. 3.3. El sector de las infraestructuras portuarias. 3.3.1. Los puertos autonómicos. 4. Diagnóstico territorial por sectores económicos. 4.1. El sector primario marino. 4.2. El sector industrial. 4.3. El sector turístico. 4.4. El sector de las infraestructuras portuarias. 5. Conclusiones para detectar la ocupación dinámica del territorio. 6. Fuentes. 7. Bibliografía.

\section{Introducción}

Este artículo propone y ejecuta una metodología para la planificación de los sistemas territoriales litorales, en un sentido conforme con la directiva del Parlamento Europeo que pide el establecimiento de un marco común para el planeamiento territorial marítimo y la gestión integrada de zonas costeras (Ferreira y Fernández, 2014), a lo que este artículo modestamente aspira a contribuir mediante el análisis de las actividades económicas presentes en una fachada litoral de escala regional. Se trata de conseguir una visión geográfica dinámica y sintética que permita detectar en el territorio litoral espacios motores y de integración. Es un propósito compartido con otros estudios, como el realizado a escala continental en Atlantic Spatial Development Perspective (CPRM, 2006), si bien aquí se concreta en el litoral asturiano, distinguiendo ahora a gran escala "sub-espacios" de distinta capacidad y dinamismo.

Figura 1. Esquema territorial de las densidades de población en Asturias en 2013

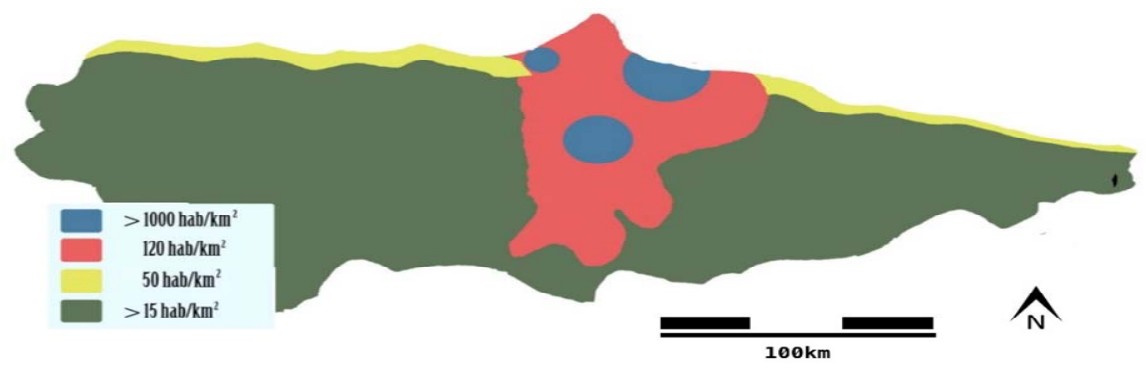

Fuente: Elaboración propia.

El litoral asturiano acoge a buena parte de la población regional y a las ciudades más dinámicas por la importancia de su actividad industriosa. Pero, además, en él se concentran las actividades agrarias más productivas, y actúa como un poderoso receptor de la difusión urbana. Si a ello se suman los espacios de interés paisajístico, para la protección de la flora y de la fauna, los aprovechamientos pesqueros tradicionales y los turísticos obtendremos un territorio caracterizado por la 
competencia entre usos. Pero esto no es general, dentro de él hay contrastes, como se deduce de la Figura 1, pues si bien hay áreas sujetas a gran presión, configuradas como espacios promiscuos, en los que la potencia del conflicto entre actividades las fragiliza, hay otras donde el dinamismo mengua y el problema viene derivado del escaso aprovechamiento de las capacidades del territorio para generar actividad económica sostenible. Conocer y valorar esta diferencia es el objeto del trabajo y una respuesta a la Estrategia Marítima Atlántica, orientada a ampliar el potencial de la “economía azul” en esta fachada europea (Rodríguez et al, 2006) y a avanzar de manera sostenible hacia una gestión integrada de estos espacios de singular clasificación (Agardy et al, 2011).

\section{El área de estudio y la metodología}

La unidad de estudio es la municipal, seleccionándose los concejos contiguos a la mar, instalados en la unidad morfo-estructural conocida como rasa costera asturiana. A escala parroquial dentro de este espacio se incluirían 218 de las 849 asturianas, las asentadas dentro de esta unidad morfoestructural. (G. P. Asturias, EIGPLA, 2015). El área de estudio abarca 25 concejos, 21 que limitan con las aguas interiores de Asturias (Avilés*, Caravia*, Carreño*, Castrillón*, Castropol, Coaña, Colunga*, Cudillero, El Franco, Gijón*, Gozón*, Valdés, Llanes, Muros del Nalón*, Navia, Ribadedeva*, Ribadesellla, Soto del Barco*, Tapia de Casariego, Vegadeo y Villaviciosa*) más cuatro envueltos en parte entre estos: Cabranes*, Corvera*, Illas y Pravia. Totalizan una superficie de $1.650 \mathrm{~km}^{2}$, el 15,5 \% de la regional, en la que reside el $46 \%$ de la población. Trece de estos concejos incluyen toda su superficie dentro del espacio litoral (los señalados con *) y los 12 restantes una parte de sus parroquias, al incluirse éstas en otras unidades morfoestructurales contrastadas con las de la rasa costera.

Figura 2. Área de estudio de las actividades litorales del Principado de Asturias y municipios que comprende

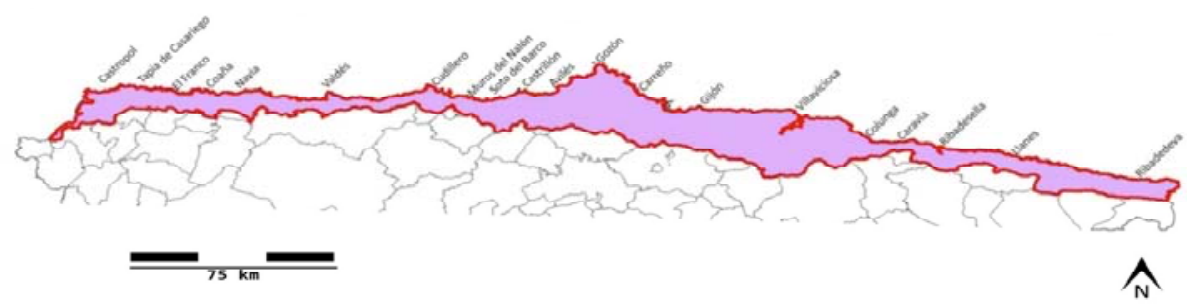

Fuente: Elaboración propia. 
Nos aproximaremos a una delimitación del espacio litoral relativa, pero necesaria, pues si consideramos una línea de 502,5 km. que corra paralela y a un kilómetro de la que delimita las aguas interiores de Asturias, comprobamos que en esa franja, que tan sólo representa el 2,9\% de la superficie regional, se concentra el $38 \%$ de la población (Nuñez y Carrero, 2013). Si la ampliamos hasta una anchura de cinco km. ubicaríamos en ella a casi la mitad de la población regional, unas 475.000 personas, y al $43 \%$ de las viviendas, en un 12,4\% de la superficie del país. La distribución de la población refleja su basculamiento hacia el litoral, pues aproximadamente ésta se distribuye a partes iguales entre la franja litoral y el interior del área metropolitana (Avilés-Oviedo-Siero-Gijón) dejando un 9\% para ocupar todo el interior. Este peso de la población litoral es equivalente a su aportación a la actividad económica regional, a la que los 21 concejos costeros aportan el $46 \%$ del valor añadido bruto regional (Gob. Pdo. Asturias, EIGPLA, 2015)

El territorio litoral asturiano comenzó a ser objeto de atención regulatoria por la administración autonómica desde 1984 cuando ésta estableció el Suelo No Urbanizable de Costas, como categoría específica dentro de las Normas Urbanísticas Regionales en el Medio Rural de Asturias, dando unas Directrices Subregionales de Ordenación del Territorio para la Franja Costera en 1991 y aprobando en 2005 el Plan Territorial Especial del Litoral Asturiano (POLA). En 215 fue aprobada la Estrategia Integrada para la Gestión Portuario-Litoral de Asturias (EIGPLA) tramitada como Plan Territorial Especial, en el que el proyecto de investigación que sirve de base a este artículo colaboró ${ }^{2}$, estudiando la base de uno de sus ejes de actuación, el de diversificación económica y la creación de empleo, a través del conocimiento de la implantación de los sectores agrícola, pesquero, industrial, turístico, de investigación aplicada y de los espacios portuarios. Para ello se siguió un proceso en tres fases: la del análisis de los sectores y subsectores; el diagnóstico en los niveles espacial, global e integral; y la monitorización, mediante la búsqueda y cualificación de las bases de datos referidas a los sectores analizados.

La metodología presenta un carácter descriptivo, con el análisis detallado de los distintos sectores significativos, que permite construir una imagen de la funcionalidad del área de estudio, imagen finalmente sintética cuando la territorializamos y distinguimos "espacios motores” y "espacios de integración”, lo que permite visualizar el grado de fragmentación del territorio a escala regional y constituye una bases para trazar políticas de ordenación regional basadas en el policentrismo. Por otro lado, la aplicación a escala regional de esta metodología se deriva de un estudio de escala continental (CPRM, 2006) en la que el equipo redactor la aplicó a toda la fachada atlántica europea distinguiendo a esa escala tales tipos de "subespacios", concluyendo que un proyecto policéntrico para la fachada atlántica

2 Proyecto de investigación: “Análisis, diagnóstico y monitorización de las actividades económicas litorales”, FUO2013, Consejería de Fomento, Ordenación del Territorio y Medio Ambiente. Gobierno del Principado de Asturias 
obligaría a tener en cuenta estas distinciones espaciales a escala regional que previamente necesitarían ser conocidas. A tal propósito sirve este artículo.

Tabla 1. Sectores y subsectores de actividades litorales significativas

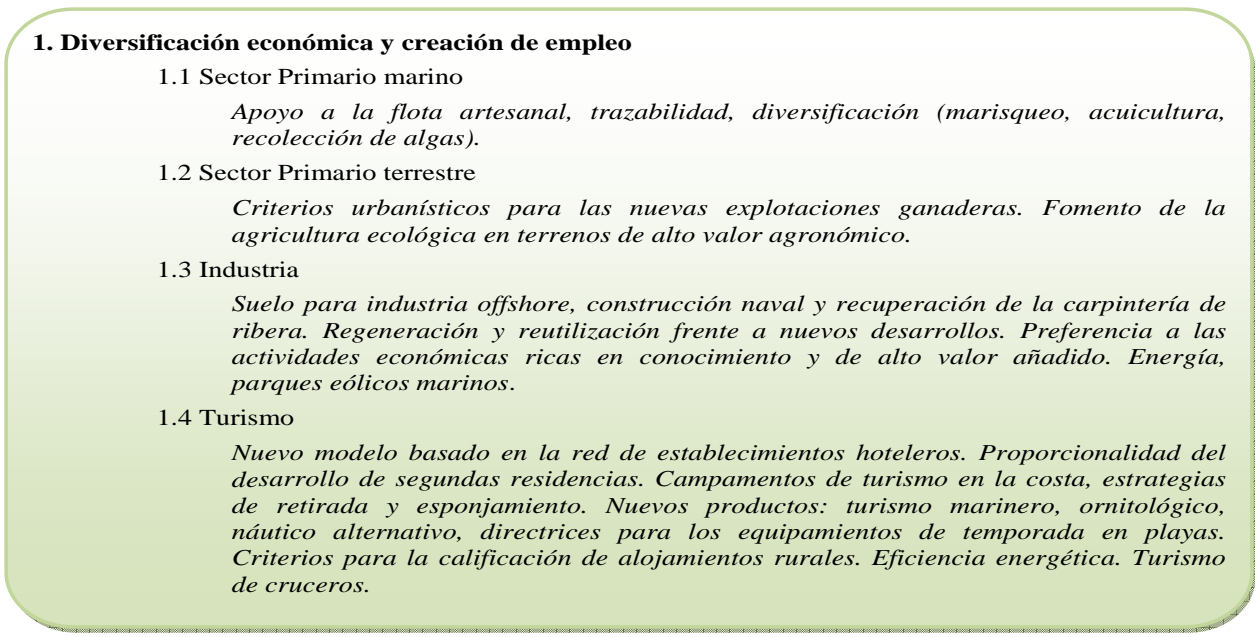

Fuente: Elaboración propia.

\section{El análisis de las actividades económicas y de los sectores de apoyo}

\subsection{El sector primario marino}

\subsubsection{El subsector pesquero}

Los 18 puertos pesqueros asturianos tienen una actividad muy desigual. Avilés destaca sobre el resto, tanto en el peso de las capturas desembarcadas (64\%) como en el valor de las mismas (61\%). Si a Avilés le añadimos Gijón, el porcentaje para ambas magnitudes llega al 87\%, de tal manera que los 16 puertos restantes apenas desembarcan pesca, siendo los de Llanes, Ribadesella, Puerto de Vega y Luarca los que registran un ligero movimiento. En estos pequeños puertos, el $80 \%$ de las capturas se comercializa en la propia localidad, a través del denominado canal HORECA (Hoteles, Restaurantes y Catering).

El número de embarcaciones pesqueras ha disminuido en los últimos dos decenios de 600 a 280 unidades; sin embargo, las capturas anuales se mantienen estables, en torno a 22.000 tn, debido a la mejora de la eficiencia marinera, de la precisión de los 
equipos de detección y a los avances en el procesado de la pesca a bordo. En 2004 entró en vigor la normativa ${ }^{3}$ que establece el sistema de control para identificar y seguir la traza del producto desde la llegada a puerto hasta su venta en pescaderías, restaurantes o grandes superficies. Para el periodo 2014-2020 se inicia un nuevo programa del Fondo Europeo para la Pesca Marítima (FEMP), con 6.500 millones de euros, que considera una ampliación de las ayudas.

Figura 3. Embarcaciones pesqueras y valor de la pesca desembarcada (2012)

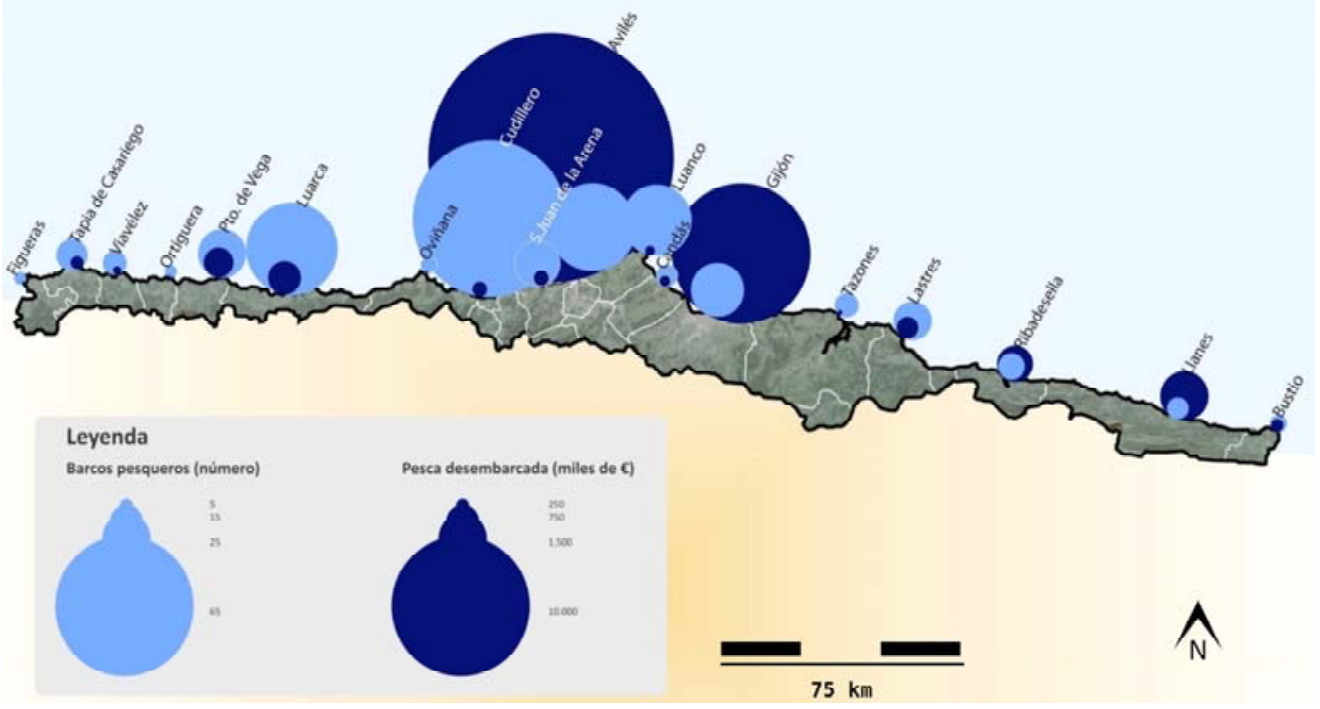

Fuente: www.sadei.es sobre datos D. G. Pesca, Gob. Pdo. Asturias y www.magrama.gob.es. Elaboración propia.

Los datos, muestran una tendencia a la disminución del número de embarcaciones que operan desde los puertos pesqueros asturianos, en total un 25\% desde 2001, y de un $18 \%$ las dedicadas a artes menores. A pesar de este descenso la cantidad de pesca desembarcada durante las dos últimas décadas permanece estable; pues si durante la década de 1990 se produjo una mengua, desde 2000 la curva se estabiliza, y vuelve a ascender durante los cinco últimos años de la serie, acercándose a los valores de 1990. Esta tendencia es más acusada si se considera el valor de la pesca desembarcada, el cual ha alcanzado los máximos de la serie durante 2010 y 2012, lo que refleja un aumento de la productividad y de la eficiencia de las embarcaciones.

3 Real Decreto 121/2004 de 23 de enero, sobre la identificación de los productos de la pesca, de la acuicultura y del marisqueo vivos, frescos, refrigerados o cocidos.( BOE $\mathrm{n}^{\circ} 31$, de 5 de febrero de 2004) 
Figura 4. Número de embarcaciones total y de artes de pesca menores por cofradía (2011)

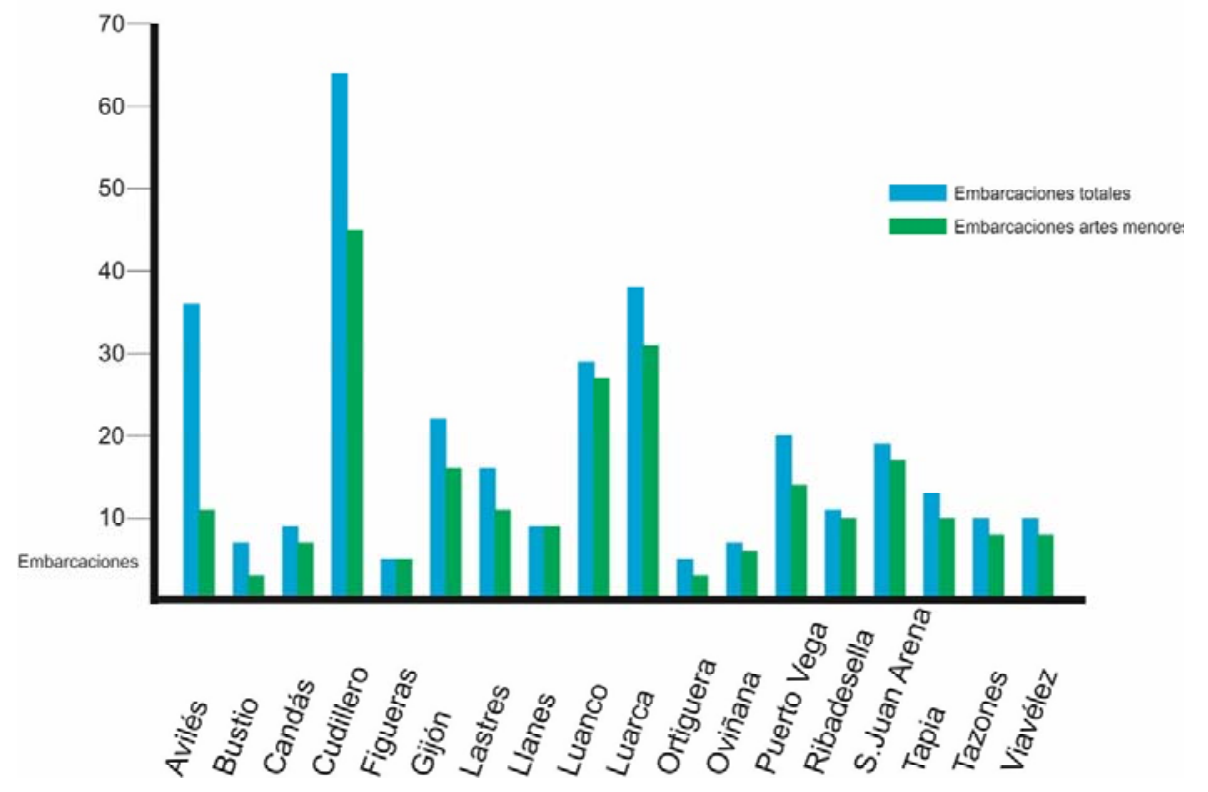

Fuente: www.sadei.es con datos D.G. Pesca, Gob. Pdo de Asturias. Elaboración propia.

Figura 5. Evolución del número de embarcaciones pesqueras totales y de artes menores (2001-2011)

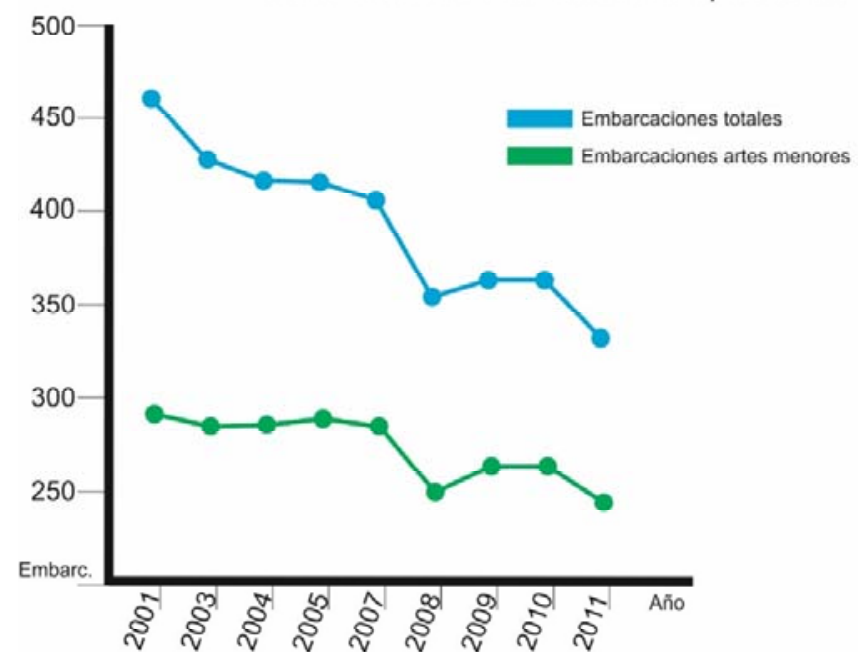

Fuente: www.sadei.es con datos D. G. Pesca, Gob. Pdo. de Asturias y www. magrama.gob.es Elaboración propia 
Figura 6. Peso y valor total de la pesca desembarcada por años (1990-2012)

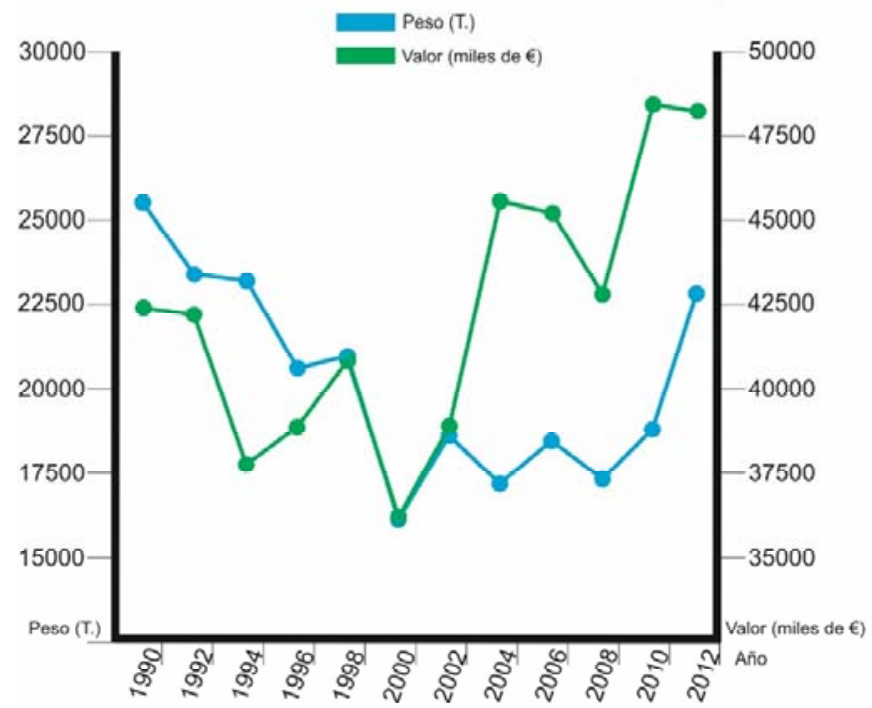

Fuente: www.asturias.es/dgpesca. Elaboración propia

Figura 7. Peso y valor de la pesca desembarcada por puertos (2012)

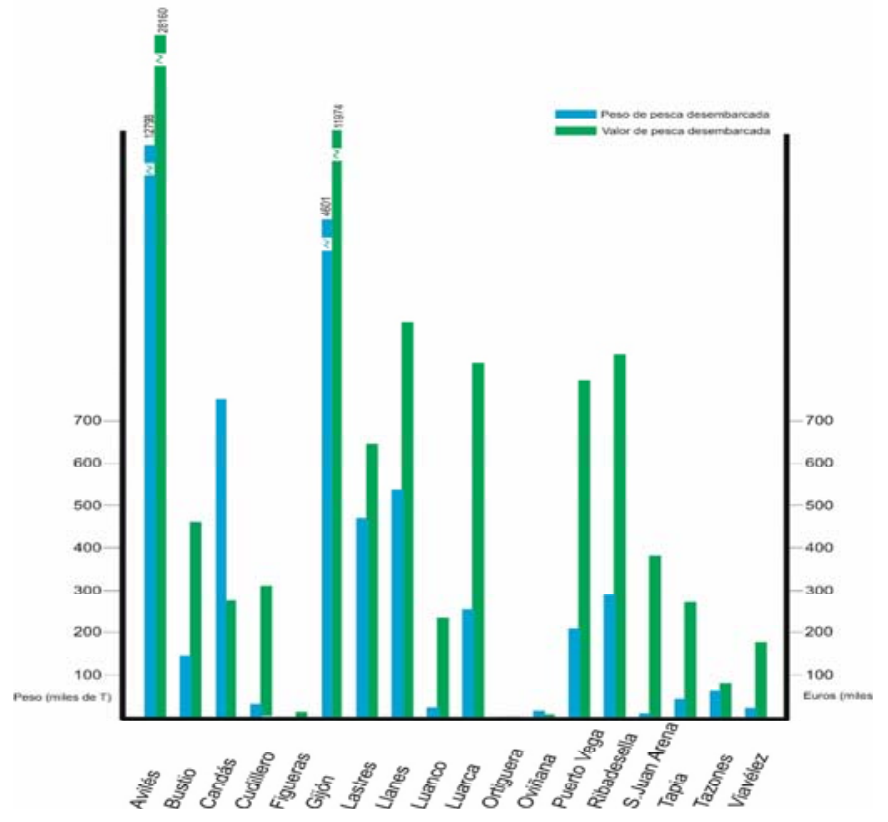

Fuente: www.sadei.es con datos D. G. Pesca, Gob. Pdo. de Asturias. Elaboración propia 
Figura 8. Evolución del valor de la pesca desembarcada por embarcación (2001-2011)

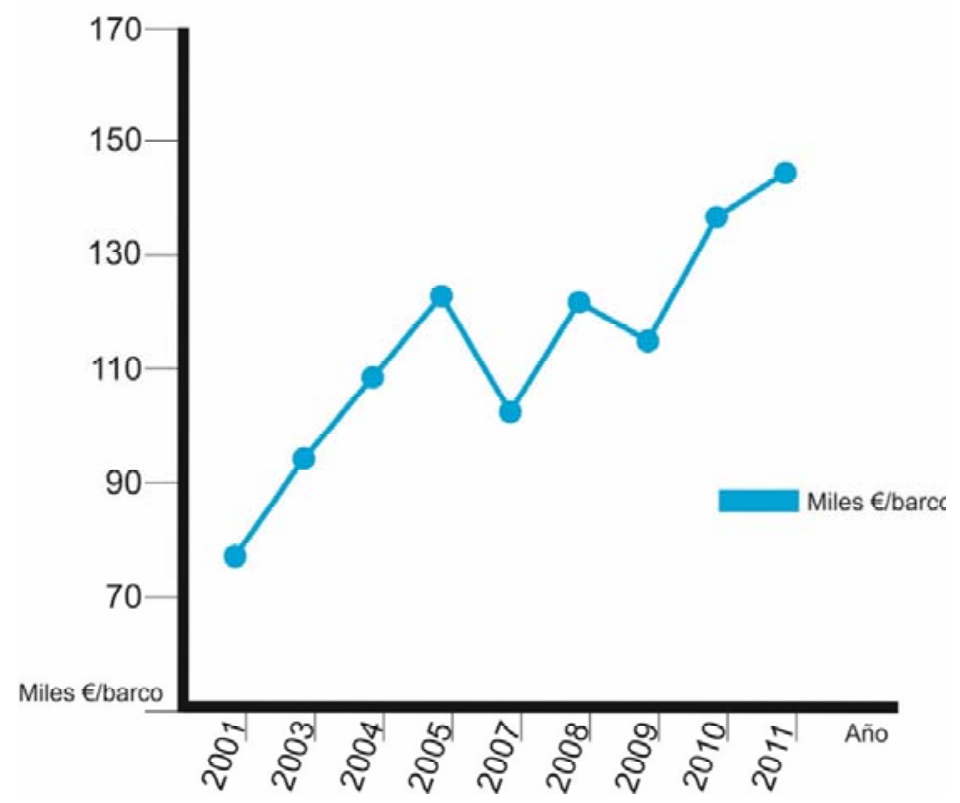

Fuente: wwww.sadei.es con datos D. G. Pesca, Gob. Pdo. de Asturias. Elaboración propia

Una de las expectativas para el subsector es la introducción del "turismo pesquero", al optimizar el uso de la embarcación, pues los descansos pesqueros se podrían dedicar a la actividad turística, permitiendo que los usuarios vivan una experiencia de pesca tradicional. Otra es la venta directa en lonja, en la actualidad únicamente permitida a minoristas, mayoristas o compradores autorizados. Estas expectativas serán alentadas por el FEMP, que elimina la subvención el desguace de embarcaciones de más de 10 años e incorpora otras destinadas a su modernización, principalmente en lo que se refiere a la habitabilidad y a la manipulación de las capturas a bordo. El FEMP potencia los “Grupos de Acción Pesquera” como gestores de desarrollo local, facilitándoles ayudas. Entre las expectativas también surge la de compatibilizar los horarios de actividad de las lonjas con los de los pescadores; para ello está en estudio la instalación en las lonjas de un sistema automático, mediante la utilización de tarjetas electrónicas, lo que mejoraría la movilidad sin perjudicar la trazabilidad. 


\subsubsection{El subsector de la acuicultura, recolección de algas y marisqueo}

La acuicultura y el marisqueo en Asturias se concentran en las rías del Eo y Villaviciosa. Según el ordenamiento jurídico ${ }^{4}$ estatal, las zonas de producción de moluscos han de cumplir con una serie de condiciones y controles que permiten clasificarlas en tres niveles: A , B y $\mathbf{C}$ en función del grado de pureza de sus aguas.

Figura 9. Distribución de la acuicultura y marisqueo en Asturias

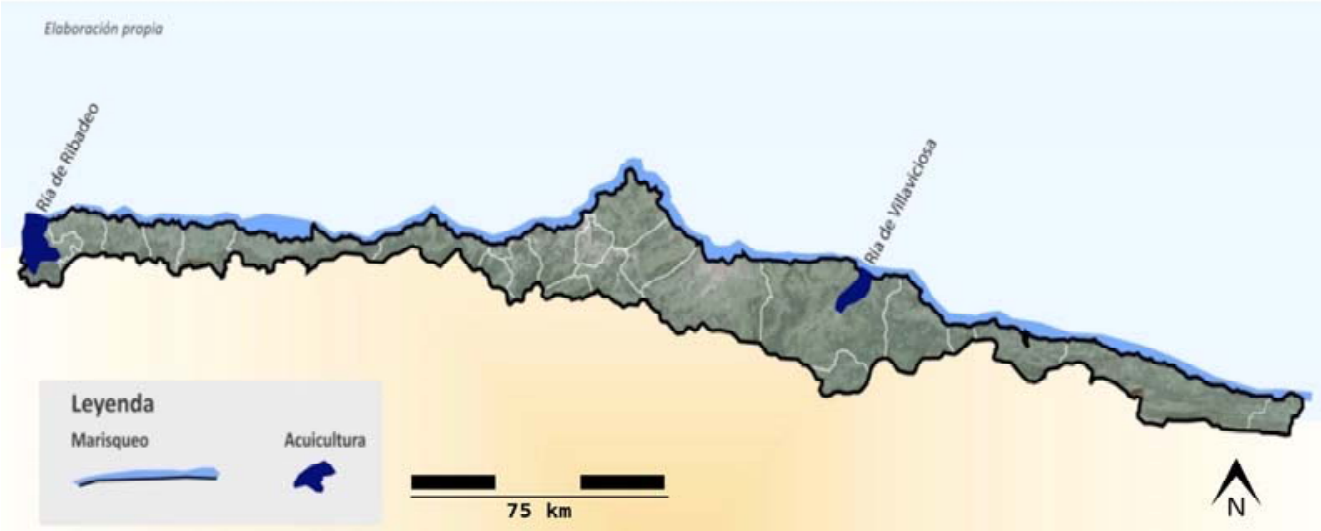

Fuente: Elaboración propia.

La ría de Villaviciosa está clasificada con el nivel C, por lo que no puede dedicarse a estas actividades hasta que la mejora de las redes de saneamiento del concejo permita recuperar la calidad del agua. La del Eo dispone de la categoría B, que exige la depuración de los moluscos antes de su venta. Funcionan dos depuradoras de moluscos, una en Tazones y otra en Castropol, las cuales emiten un certificado de salubridad para cada lote depurado que los califica como aptos para el consumo. El resto del litoral entre la ría del Eo y la de Tina Mayor, está encuadrado en la categoría A y en él se realizan labores de marisqueo con embarcaciones de bajura, que capturan erizos de mar y moluscos gasterópodos. Tanto la acuicultura como el marisqueo están orientados a mercados de proximidad.

4 Orden ARM/2243/2011, de 22 de julio, por la que se publican las nuevas relaciones de zonas de producción de moluscos y otros invertebrados marinos en el litoral español. 
Actualmente se controlan las campañas anuales de recogida de "ocle" (Gelidium sp) por buceadores en el submareal, quedando libres las que llegan a la costa a consecuencia de los temporales, las de arribazón. El Centro de Experimentación Pesquera está realizando estudios para cultivar algas de diferentes especies; apartir de uno de ellos, llevado a cabo en Lastres, se va a desarrollar una producción industrial en la misma localidad, ahora en trámites de concesión administrativa.

El subsector de la acuicultura experimentó un descenso notable de la producción en lo que va de siglo. El valor económico de la producción se sitúa en 2011 por debajo de la mitad de los valores registrados en sus comienzos. Si bien la actividad tendía ya a descender antes del cierre de la ría de Villaviciosa, su reapertura podría revertir la tendencia. El descenso en la producción acuícola no se ha traducido en una pérdida equivalente de puestos de trabajo. Se han perdido unos cincuenta puestos durante los últimos años, pero en 2011, a pesar de no existir un repunte en la producción, se produjo un aumento en el total de empleos, ligado a formas no asalariadas, lo que puede reflejar la precarización del mercado laboral asociada a la crisis.

Figura 10. Producción de la acuicultura en Asturias en miles euros por año (2002-2011)

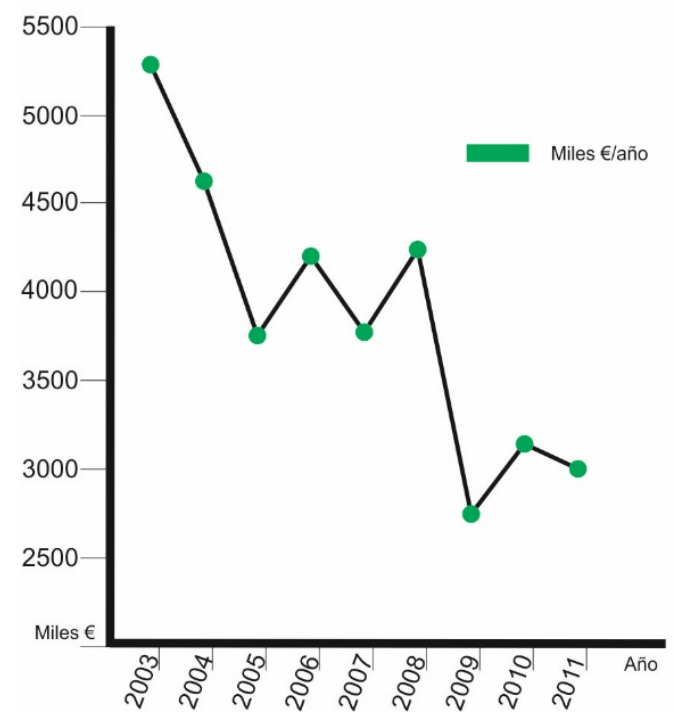

Fuente: www.magrama.gob.es 
Figura 11. Evolución del empleo en acuicultura en Asturias (2002-2011)

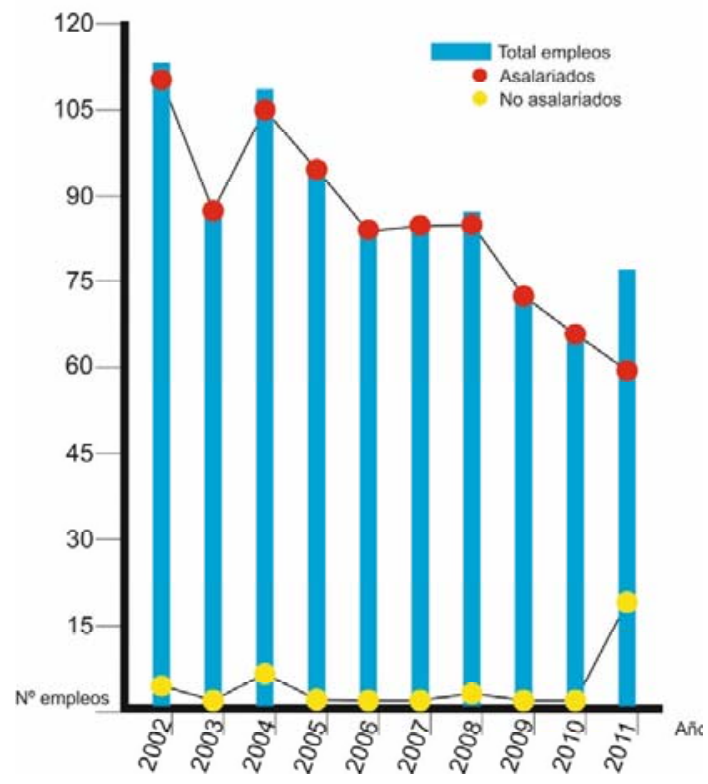

Fuente: www. magrama.gob.es

La ordenación integral de las rías es una de las principales necesidades para el fomento de la acuicultura y el marisqueo, especialmente urgente en la de Villaviciosa. En ella y en la del Eo es de gran importancia el mantenimiento y recuperación de sus canales naturales, lo que facilita la navegación; a la vez es necesario estabilizar el sustrato de la ría, generalmente de arena y fango, para favorecer la supervivencia de las poblaciones de moluscos, cuestiones contradictorias y por ello de complicada gestión.

El Fondo Europeo para la Pesca Marítima en su programación 2014 - 2020 establece líneas de ayuda para potenciar la acuicultura en mar abierto (offshore). La orografía acantilada de la costa asturiana implica grandes costes de bombeo para las instalaciones en tierra; las figuras de protección ambiental en las áreas más bajas, donde el coste de las instalaciones sería menor, impiden la ubicación de infraestructuras básicas para tales instalaciones. Dado que en la actualidad se ha producido un considerable avance en la construcción de las estructuras de cultivo, la producción offshore se revela como una opción a estudiar, si bien lastrada por el carácter abierto de la costa y los periódicos temporales que corren el turbulento Cantábrico. 


\subsection{El sector primario terrestre}

\subsubsection{El subsector ganadero}

Los concejos litorales presentan una concentración de explotaciones vacunas de orientación lechera, especialmente los de la franja occidental, sobresaliendo el de de Castropol (2,1 UG/persona). La expansión del subsector, en un ciclo de reducción de costes externos, está gravada por la escasez del suelo agrario disponible para aumentar la base territorial de las explotaciones. Hay una fuerte competencia con los usos del suelo de carácter urbano. Las expectativas ligadas a su calificación urbanística paralizan la expansión de las explotaciones; también surgen otros conflictos entre propietarios ganaderos y residentes temporales, derivados de la promiscuidad de usos, como los motivados por los olores y ruidos generados por las explotaciones, especialmente en la gestión de los purines, necesitada de mejoras para desodorizarlos y modificar su estado físico. La necesidad de tratamiento de los purines ha impulsado la construcción de la primera estación de este tipo en Asturias por la empresa Biogastur, que a partir de ellos genera electricidad, además de transformarlos físicamente para favorecer su almacenamiento. Del subproducto obtenido se conoce su composición exacta en nitratos, por lo que se puede controlar el nivel de nitrógeno contenido en las tierras de aprovechamiento agrario.

Figura 12. Cabezas de ganado (UG) por habitante y concejo en 2012

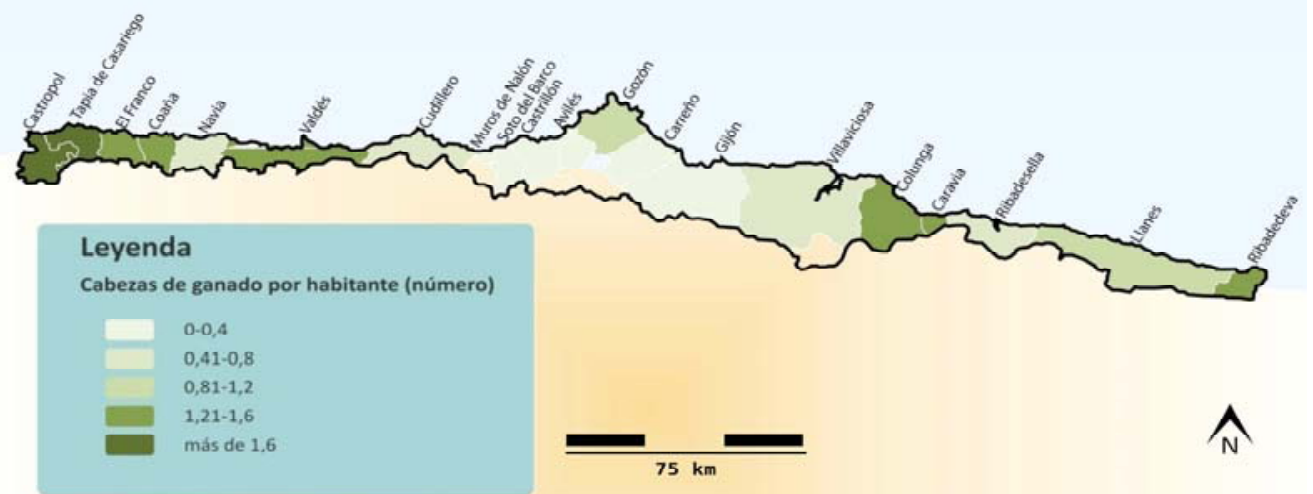

Fuente: www.sadei.es (2013) 
Figura 13. Cuota láctea por concejos en kg (2012).

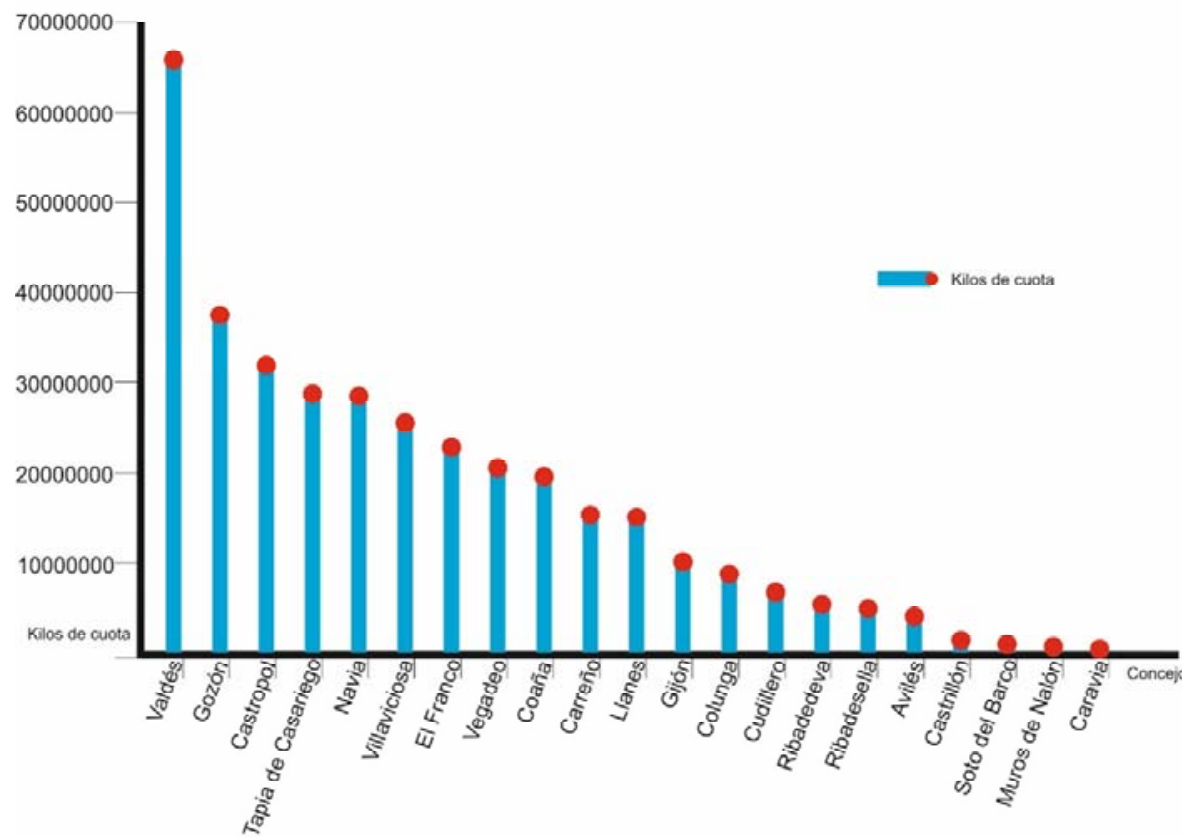

Fuente: www.sadei.es/datos (2014)

El reparto de la cuota láctea se mantiene estable desde hace veinte años. Son los municipios litorales del área occidental los que acaparan la mayor parte de la misma, superando, en una proporción de dos a uno, a la suma de las cuotas en las áreas central y oriental. De ellas, la central presenta un marcado ascenso de cuota desde 2004 frente a la oriental, invirtiéndose así la tendencia anterior. Si bien la cuota global se mantiene constante, el número de titulares de la misma disminuye de manera continuada, componiendo una situación similar a la del subsector pesquero: descenso del número de titulares y mantenimiento de la producción, que resulta de una mayor productividad individual y una progresiva concentración de la actividad. Desde abril de 2015 se abrió un nuevo horizonte para las ganaderías de leche, ya que desaparecieron las cuotas lácteas ${ }^{5}$ que en España venían regulando el mercado desde

5 Cuota láctea: Cantidad de referencia individual de leche, expresada en kilogramos y vinculada a un coeficiente de materia grasa expresada en porcentaje, asignada a cada explotación. Esta podrá dividirse, en su caso, en entregas o en venta directa., regulado por Reglamento (CEE) 856/84 "Régimen de cuotas lácteas y su correlato de la tasa suplementaria a pagar por el exceso de producción en relación con las cuotas máximas anuales asignadas a cada Estado miembro" 
Figura 14 .Cuota láctea y número de titulares por sectores de litoral (1993-2012).

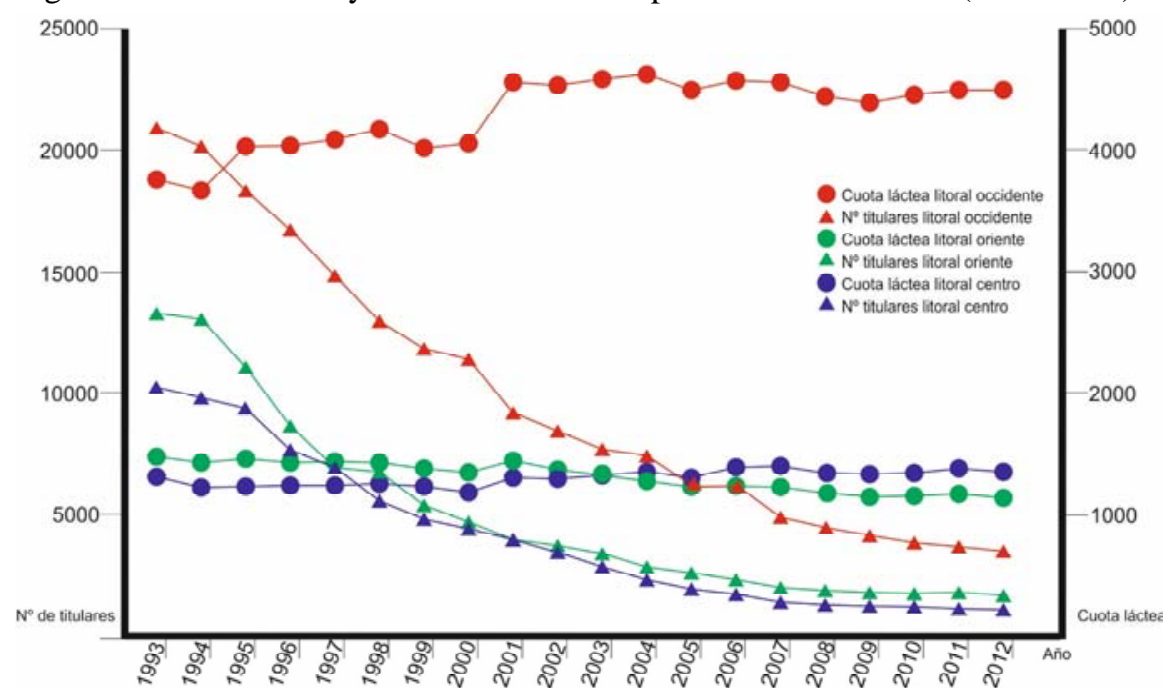

Fuente: www.sadei.es/datos

\subsubsection{El subsector agrícola}

La franja litoral dispone de unas condiciones agronómicas adecuadas para el cultivo manzano - pradería, que constituía su especialización histórica. La competencia de otras actividades en la franja litoral hace que la producción agrícola tienda a descender salvo excepciones, como son los cultivos ecológicos, los de nueva introducción o el autoconsumo. Al igual que sucede con el subsector ganadero, la mayor concentración de esta actividad se da en el ala occidental; donde, si bien, la producción ha descendido significativamente durante los últimos cinco años, aún ofrece una producción agrícola más de dos veces superior al resto de los concejos litorales, siendo Castropol y Tapia de Casariego los que, como en el caso del subsector ganadero, presentan la ratio más elevada de producción por habitante. El sector central y el oriental ofrecen valores similares entre ellos, si bien la tendencia del central es a la estabilidad y la del oriente al descenso, acusado entre 2006 y 2008. Las expectativas urbanísticas han elevado el precio del suelo agrario, lo que unido al envejecimiento de la población, hace abandonar su cultivo. La producción hortícola, orientada al autoconsumo o a la comercialización local, se ha mantenido estable; si bien, actualmente hay un ligero repunte, al que contribuyen los invernaderos concentrados en Gozón y en la cuenca del Navia, sostenidos por los acuerdos alcanzados con la distribuidora de productos hortícolas frescos "Feito y Tollosa". La modernización de las explotaciones, así como a la incorporación de jóvenes al sector está contribuyendo a este repunte, incentivado también por el aumento de distribuidores que comercializan productos de las huertas asturianas, pues su ausencia 
era uno de los factores limitantes para el subsector. Todo ello ha fomentado el desarrollo de nuevos cultivos como grosella, frambuesa, fresa, kiwi y arándano, producto éste último demandado en los mercados del norte de Europa y en el Reino Unido, y cuya producción en Asturias se ve favorecida por una ventaja competitiva, derivada de su salida anticipada al consumidor.

Figura 15. Producción agrícola en toneladas por concejo (2012)

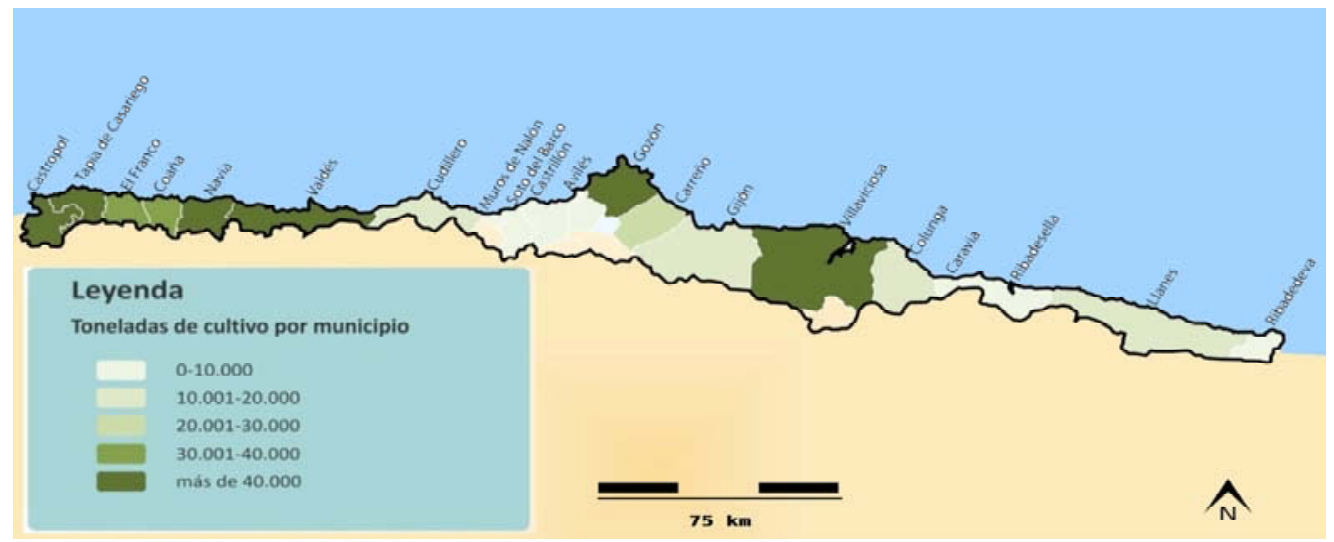

Fuente: www.sadei.es sobre datos Censo Agrario Elaboración propia

Figura 16. Producción agrícola por áreas en miles de tn (2006-2010).

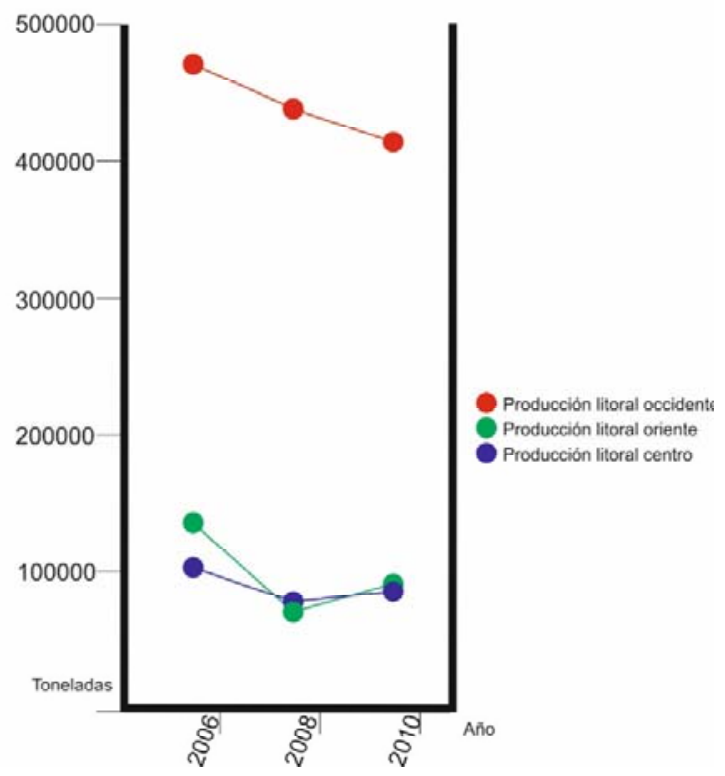

Fuente: www.sadei.es sobre datos censo agrario Elaboración propia. 
Figura 17. Producción agrícola por habitante (2010)

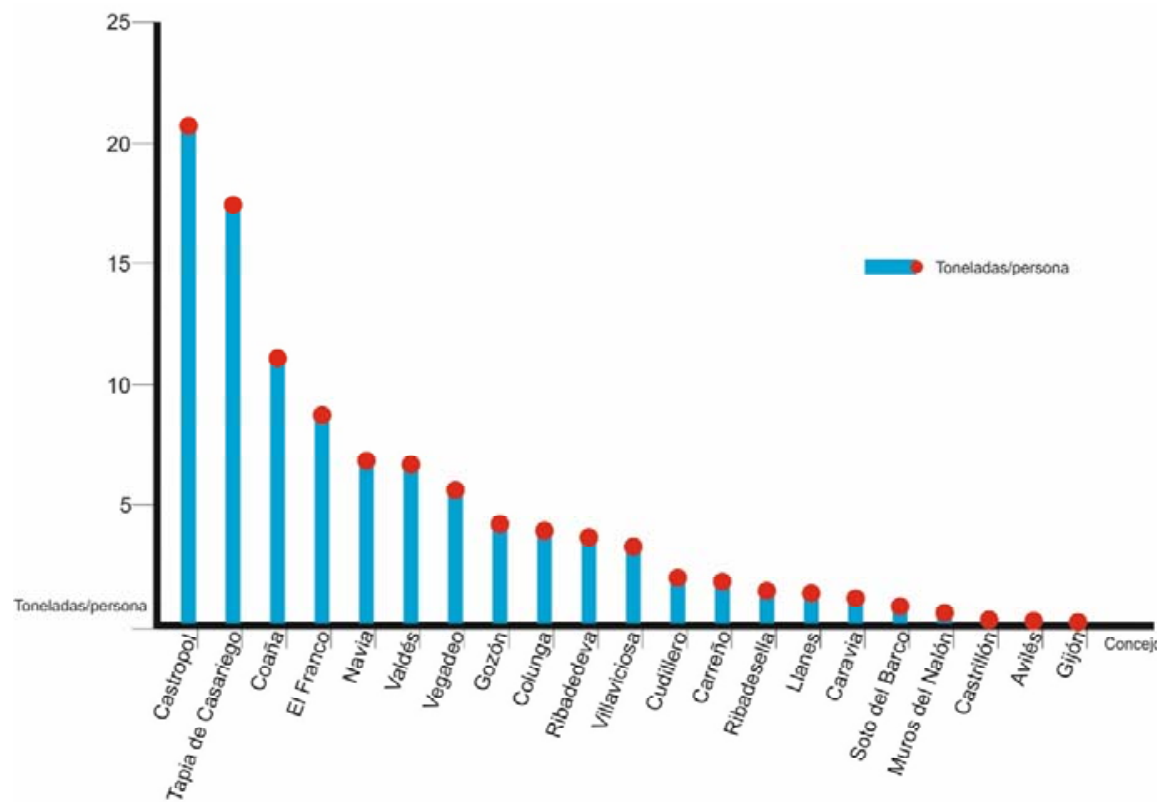

Fuente: www.sadei.es. Elaboración propia

Figura 18. Cortas de madera por concejo (2011)

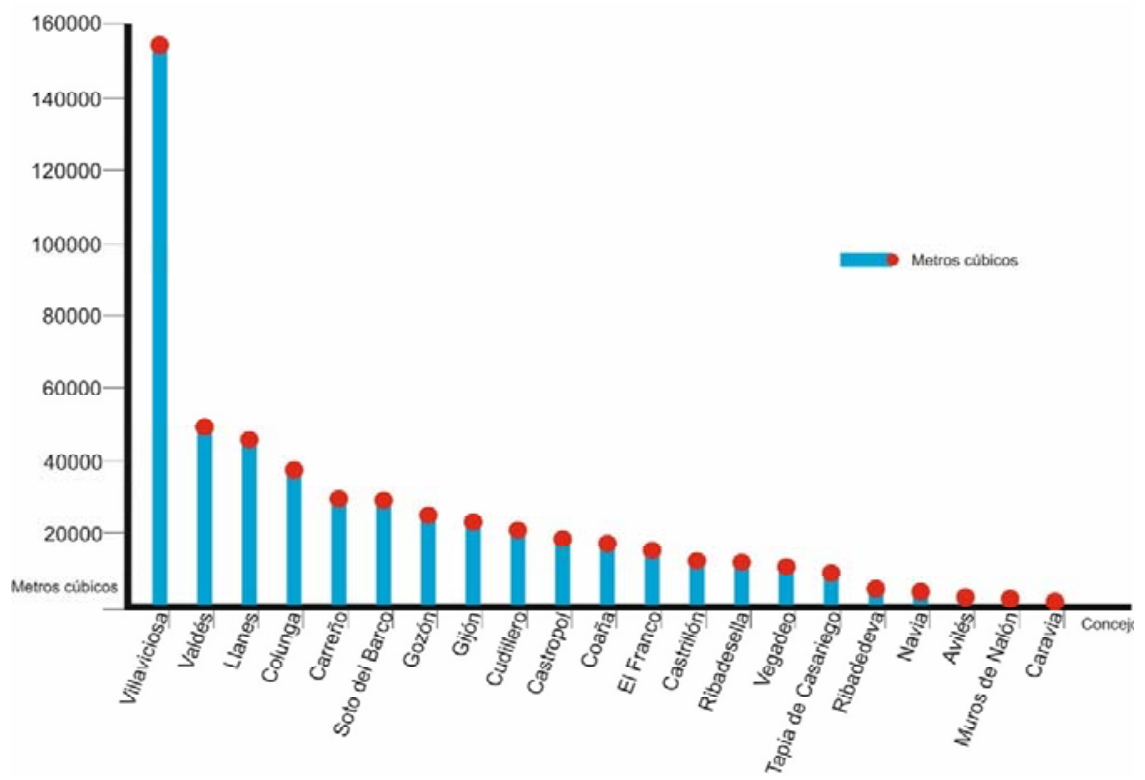

Fuente: www.sadei.es. Elaboración propia. 
Los concejos litorales registran importantes plantaciones de eucalipto y pino, cultivos energéticos dedicados a la creación de biomasa, en expansión debido a las circunstancias generales ya expuestas, a la facilidad para mecanizar su proceso productivo y a la escasas labores de mantenimiento que requiere su cultivo.

La agricultura ecológica está enfocada a la venta local o en comercios especializados pero no representa un volumen significativo de ventas, registrándose productores más o menos aislados, algunos en ámbitos urbanos y con un claro matiz alternativo, vinculados a la utilización de nuevas tecnologías de la información.

Una de las tendencias para el subsector agrícola es la orientación hacia el comercio de proximidad asociado a la imagen de marca de calidad agro-alimentaria ligada a la temporada y a la producción local, revitalizándose culturalmente los mercados locales tradicionales con la gastronomía y el turismo. La expansión de los cultivos de frutos rojos parece segura, derivada de su rentabilidad (alto valor de mercado y rendimiento a partir del cuarto año del inicio del cultivo) y de las buenas condiciones agronómicas.

\subsubsection{El sector industrial}

\subsubsection{El subsector de la industria naval}

Está representado en cinco localidades y en otra es de carácter artesanal. Entre 2006 y 2009 conoció un importante crecimiento; en los siguientes, las incertidumbres derivadas de la crisis europea y del caso "tax lease" provocaron su retroceso. La construcción naval está estrechamente unida al sector bancario, pues los altos costes de fabricación necesitan de complejas operaciones financieras. Por ello, la situación del sector financiero incidió con especial gravedad en este subsector. La apertura de líneas de crédito y la resolución del denominado "tax lease" están mejorando su situación, aunque el subsector dejará de ser preferente y por ello competirá en régimen abierto con otros industriales por las ayudas gubernamentales.

Figura 19. Distribución de la construcción naval en el litoral asturiano y botaduras de buques (2004-2013).

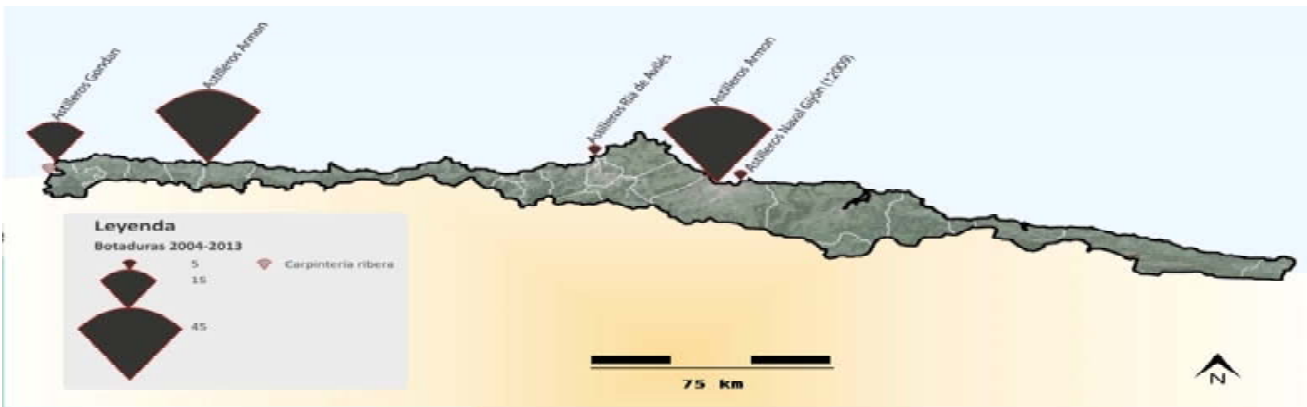

Fuente: Elaboración propia a partir de datos de la Gerencia de Construcción Naval, www.gernaval.org 
Los datos de botaduras muestran el arraigo del subsector en Asturias, con una producción continuada durante las últimas décadas, que se sobrepone a las coyunturas económicas y al continuo proceso de reestructuración que experimenta y que refleja la Figura 23 , pues incluye a empresas que no pudieron superar tales procesos y que dejaron de operar en la última década (Naval Gijón), junto a otras (Astilleros Ría de Avilés) que retoman la producción, aunque sea con cifras modestas, a partir del 2006.

Figura 20. Evolución de las botaduras en astilleros de Asturias (1999-2013)

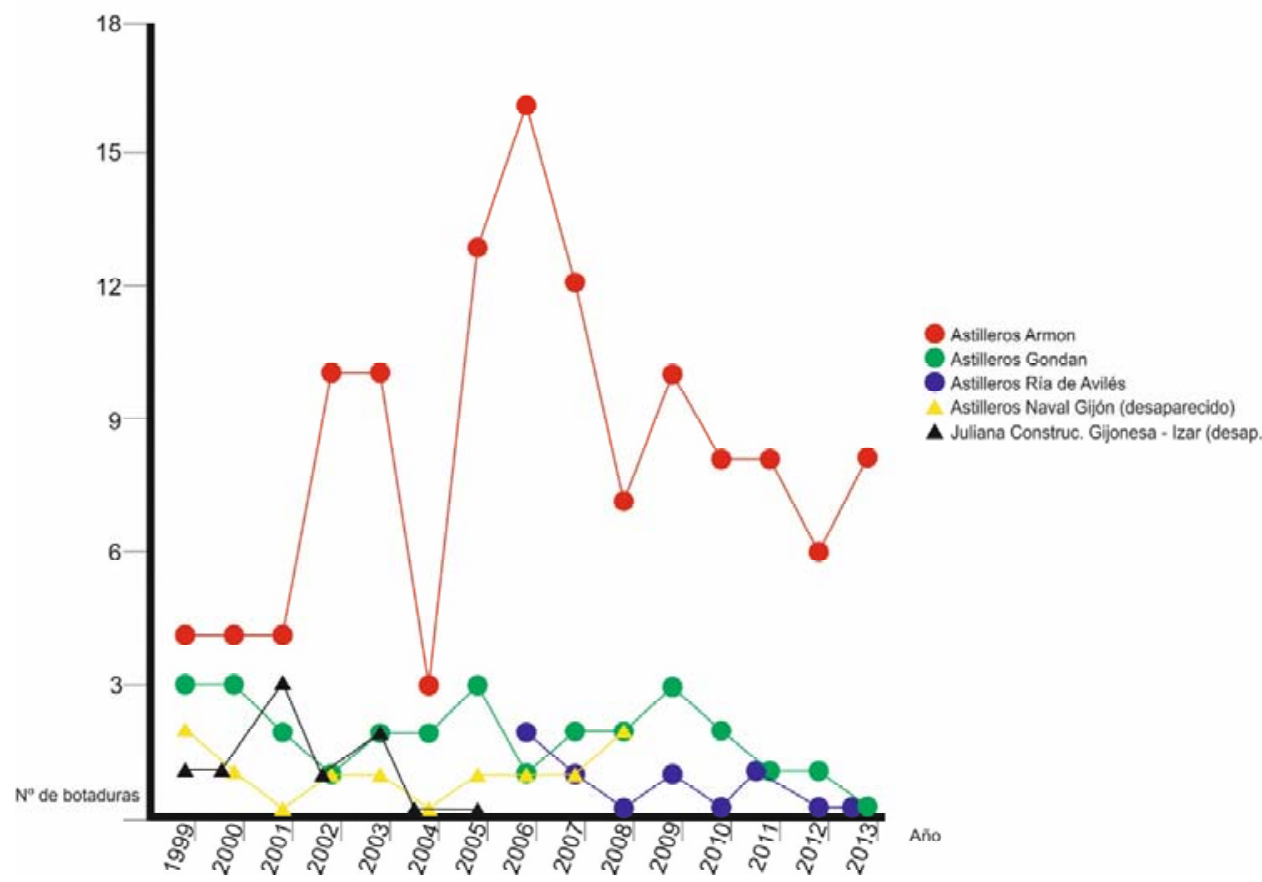

Fuente: www.gernaval.org

La actividad sigue impulsada por la empresa Astilleros Armón que, tras un máximo de producción entre 2005 y 2008, bota al año entre siete y nueve barcos, y Gondán con cifras inferiores. Las necesidades de los astilleros asturianos están relacionadas principalmente con sus localizaciones, ya que su ubicación en la vecindad de núcleos de población y en espacios portuarios limita su expansión y aprovisionamiento. Igual que su localización en las rías, del Eo y Navía, pues el calado de acceso a los diques y muelles de construcción necesita constantes obras de dragado y aún así apenas se consigue un nivel mínimo de calado y de maniobra, que suple la pericia de los equipos técnicos de las empresas. 
En Asturias, la última embarcación de pesca con casco de madera se construyó hace poco más de 15 años. El único astillero asturiano que trabaja con este material se encuentra en la ría del Eo y cuenta con un trabajador, el propietario, que repara y fabrica embarcaciones de recreo de gran calidad y precio a la altura de la misma. La falta de suministradores locales encarece y dificulta la fabricación artesanal; que también se ve afectada negativamente por los trámites administrativos necesarios para obtener plaza en los pantalanes, ya que la embarcación tiene que estar registrada y para ello ha de estar construida. El tiempo medio de construcción de una embarcación en este astillero es de tres meses, por lo que sería necesario revisar y cambiar los requisitos de los trámites administrativos para este tipo de embarcaciones históricas. El peligro de desaparición de la carpintería de ribera justifica el establecimiento de una línea de ayuda urgente y específica para la conservación de este arte de construcción.

\subsubsection{El suelo industrial}

La industria ha contribuido decisivamente a levantar un distrito industrial en el área central asturiana que, con el paso de los años y las reestructuraciones territoriales, se ha transformado en el área metropolitana que hoy conocemos. Gijón y Avilés son los concejos que mayor superficie de suelo industrial acumulan y en la que acogen a las principales empresas industriales de la región (Arcelor-Mittal, Alcoa, Fertiberia, Asturiana de Zinc, EDP, Dupont, cementeras, metalmecánicas...). Ambos irradian instalaciones industriales hacia su entorno inmediato, Carreño y Gozón, que ofrecen suelo industrial abundante, conformando en el interior metropolitano un área de especialización industrial, que une Gijón y Avilés a través de los dos concejos señalados. Los ubicados en las franjas laterales, además de la industria de construcción naval y papelera, presentes en el occidente, ofrecen datos más bajos y relacionados con la localización de fábricas e instalaciones que dan servicio principalmente a sus entornos, configurando un esquema de cabeceras y espacios de transición entre ellas. Al oriente es Llanes el concejo que concentra más suelo industrial y ejerce como cabecera comarcal. En la franja occidental destaca el polo Navia-Coaña. La actividad generada por Navia, cabecera industrial del occidente asturiano, la aprovecha Coaña, al disponer de suelo que ha sido urbanizado para usos industriales, de servicios, sanitarios y de otro tipo. Valdés actúa como cabecera secundaria, con valores de suelo industrial apreciables, aunque por debajo del anterior. 
Figura 21. Suelo industrial por concejos en m² en 2011.

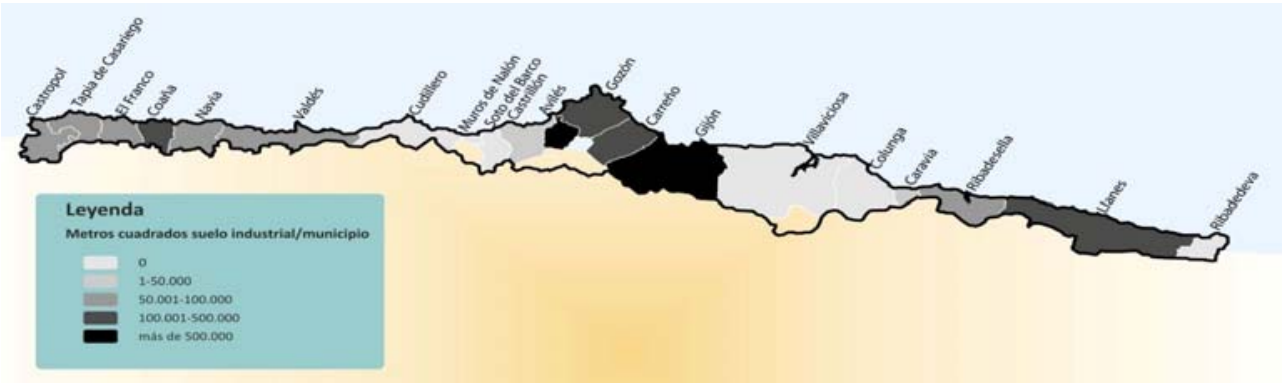

Fuente: Elaboración propia a partir de www.idepa.es

Figura 22. Superficie de suelo industrial por concejos en $m^{2}$ (2011)

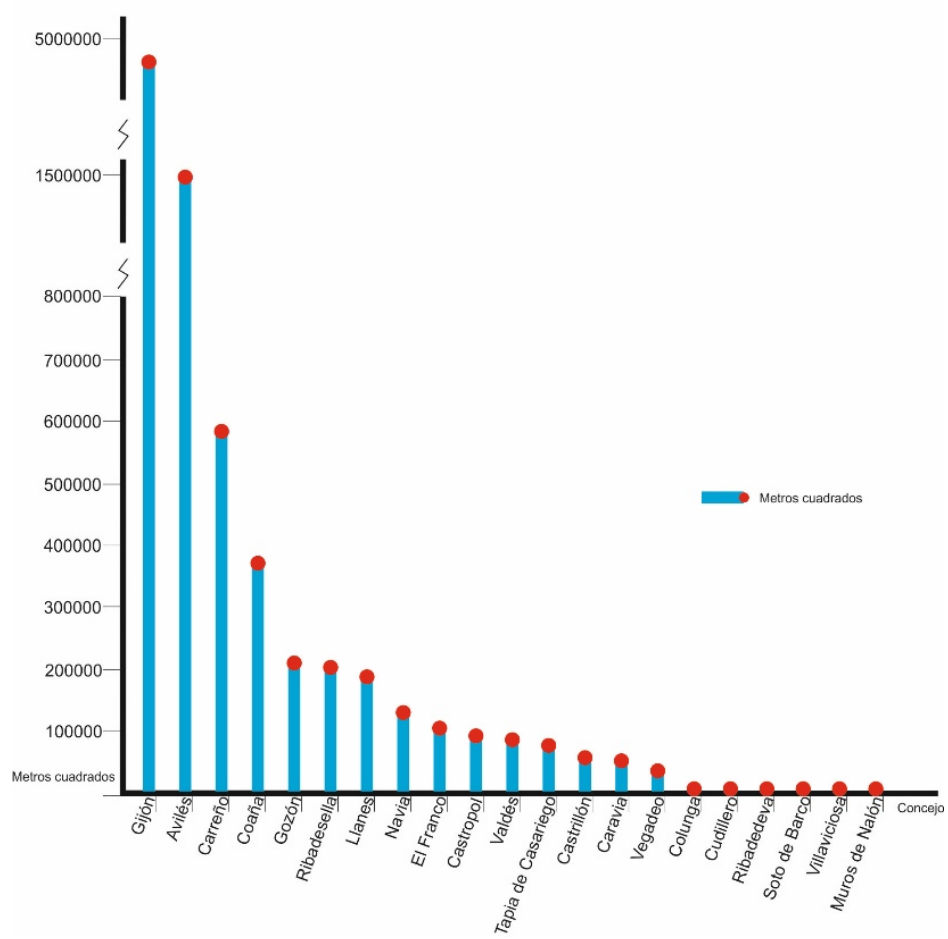

Fuente: Elaboración propia a partir de datos www.idepa.es 
Dos subsectores industriales con fuerte implantación en la franja litoral son los que engloban a las empresas metalúrgicas y papeleras, focalizadas en Gijón y Avilés, las primeras, y en Navia, las segundas; donde mantienen su presencia aunque han experimentado una reducción en el número de empleados, derivado de los procesos de ajuste y modernización de sus plantas, que siguen manteniendo sus niveles de producción. Las empresas metalúrgicas que mantuvieron un volumen de empleo próximo a los 11.000 trabajadores a comienzos de siglo, en 2011 empleaban a cerca de 9.000 trabajadores, mientras que la factoría papelera con un máximo de 650 en 2005 había reducido la cifra de empleados a 550 en 2011.

\subsubsection{El sector turístico}

Pasa por un momento de expansión, impulsado por el aumento del número de plazas turísticas en el litoral, concretamente en el oriental, donde en las dos últimas décadas el sector ha experimentado un incremento notable del número de establecimientos hoteleros, fomentado por la mejor accesibilidad relativa, la proximidad de paisajes muy contrastados y bien conectados, el trabajo de promoción y mejora de la oferta y la diversificación de la misma, enganchándose a los nuevas tendencias, como las del turismo de aventura y de naturaleza. La costa occidental, aunque también ha tenido un crecimiento notorio, se ha visto lastrada por su aislamiento, por su inclusión en una subregión más amplia y por no haber fijado con claridad sus objetivos de desarrollo turístico, lo que justifica que no disponga actualmente de tanta oferta de alojamientos ni de actividades turísticas como la oriental, a pesar de las capacidades que tiene para ciertos deportes náuticos, como el surf o la vela. El Camino de Santiago por la costa registra un paulatino y sostenido aumento del número de peregrinos que lo transitan. La reciente conclusión de la Autovía de la Costa ha aligerado del tráfico la antigua N634 , una carretera de interés paisajístico, que ya no actúa como colector de base sino como referente para el ciclismo y el motociclismo, a la cual conectar otras espectaculares vías interiores para formar anillos de interés cicloturístico.

El número de plazas crece en todas las áreas de litoral, si bien lo hace desde distintos niveles de partida y a ritmos diferentes. Si las actividades relacionadas con el sector primario en Asturias se concentran fundamentalmente en el occidente y las de corte industrial lo hacen en el centro, la especialización turística se encuentra en el oriente. Además, el crecimiento en ésta subregión es más acusado que en las otras dos, que han conocido periodos de estancamiento o incluso de descenso (2004-2006 y 2011-2012 en el occidente; 2009-2011 en el centro) por lo que las diferencias respecto del área oriental tienden a aumentar año a año. 
Figura 23. Plazas de alojamiento colectivo por concejo (2012).

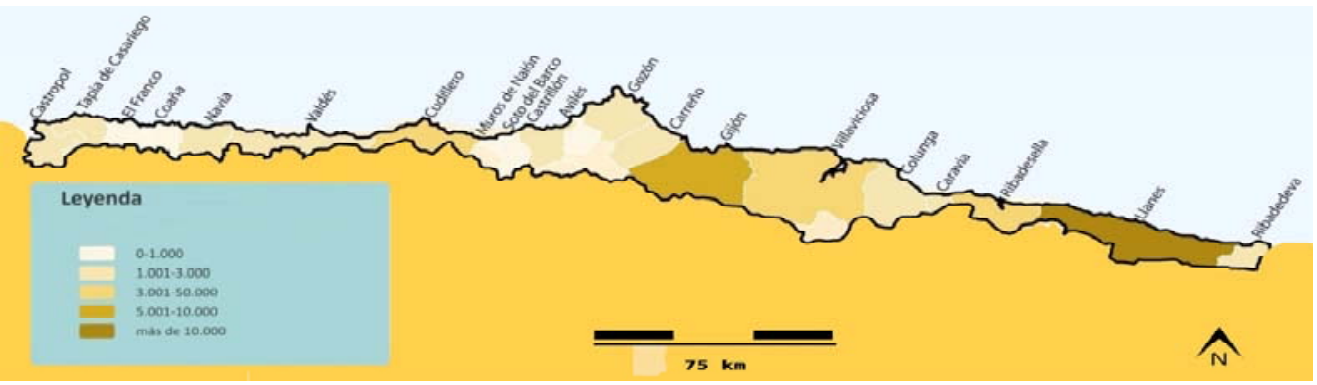

Fuente: Elaboración propia a partir de datos en www.sita.org

Figura 24. Clasificación de los concejos por número de plazas de alojamiento colectivo (2012) y plazas de alojamiento colectivo por áreas (2004-2012).

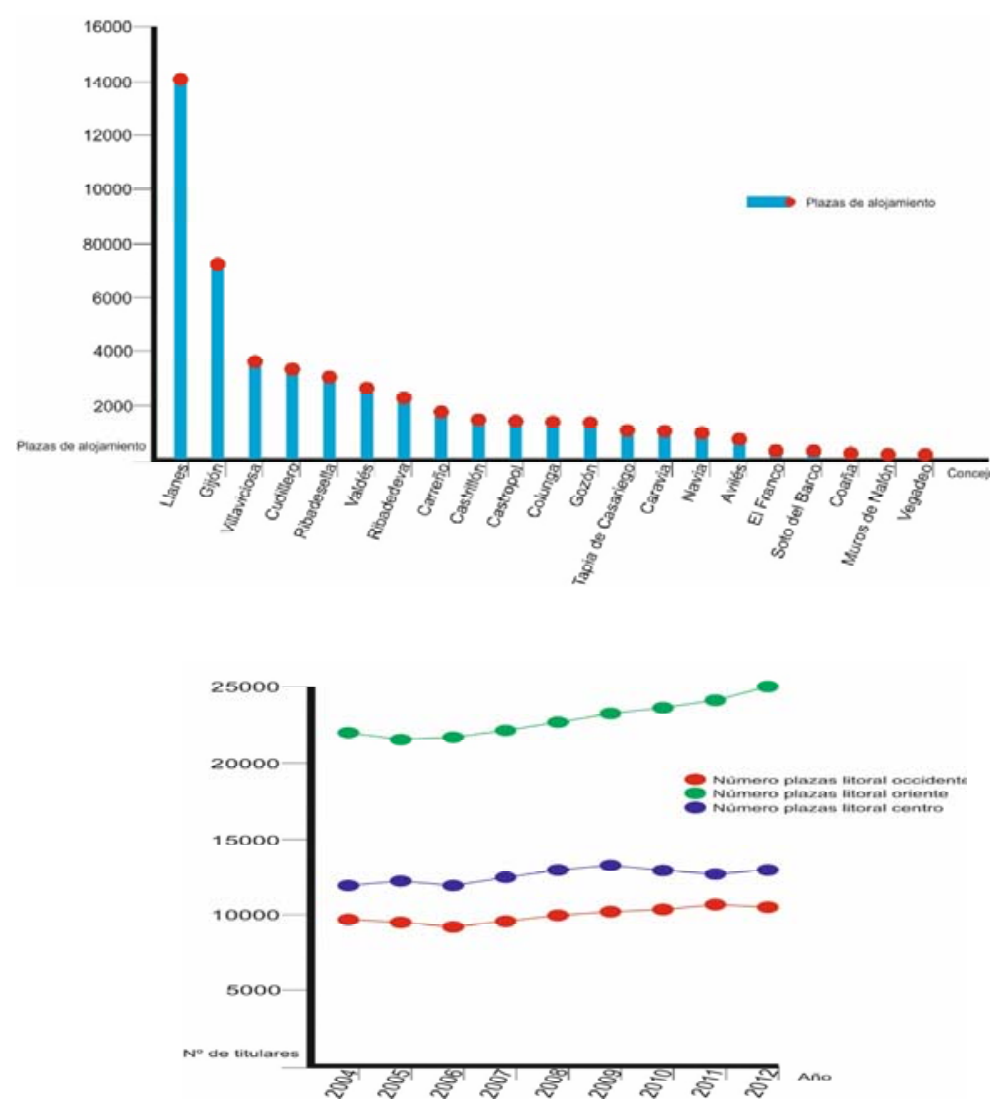

Fuente: Elaboración propia a partir de datos en www.sita.org 
Asturias dispone de 24 puertos autonómicos, con una clara orientación deportiva. Sin embargo, no se dispone de plazas en pantalanes para el tráfico turístico costero de corta estancia. Por otra parte, el sistema de tramitación de permisos de pesca deportiva es complejo y enfocado al usuario regional y no al foráneo, enfrentado a engorrosos trámites para conseguir licencias temporales.

Las expectativas son de crecimiento sostenido para el turismo en Asturias; entre otras razones por el amplio recorrido de un sector poco significativo hasta el momento, cuya imagen se había oscurecido ante otros sectores de implantación tradicional. El sector utiliza una imagen basada en la excelencia, que dan los valores naturales del territorio, su paisaje original y de atractivos contrastes fácilmente experimentables con seguridad, y unos servicios de calidad y a buen precio. El turismo náutico parte de un desarrollo muy bajo y tanto el tradicional como los nuevos productos podrán beneficiarse del apoyo de líneas financieras europeas.

\subsubsection{El sector de la investigación e innovación}

En el ámbito de la investigación e innovación es difícil ceñirse únicamente a la franja litoral. Por eso, su análisis se plantea desde una visión regional. Aunque el Gobierno asturiano destina más recursos a la investigación básica que la media de los gobiernos regionales, los grupos de investigación captan fuera un porcentaje superior a la financiación aportada por el gobierno regional. Este establece una partida destinada a I+D+I que se ejecuta en una serie de convocatorias orientadas también a las empresas. Las más grandes son las que disponen de medios adecuados para poder solicitar con pertinencia estas ayudas. Las pequeñas no disponen de personal cualificado para poder redactar las memorias técnicas o, simplemente, no son conscientes de cómo integrar la investigación en su proceso productivo.

Es importante resaltar que en Europa el $66 \%$ de la financiación de la I+D+I procede de empresas privadas, en España el $55 \%$ y en Asturias el porcentaje se reduce al 33\%. Tras el acuerdo de la Comisión Europea sobre "Estrategias de Investigación e Innovación para la Especialización Inteligente RIS III”, la región debe fijar sus prioridades en función de sus capacidades, siendo las relacionadas con la mar una de las grandes líneas estratégicas.

La recesión económica ha cortado la tendencia alcista, que se mantenía desde 2000, de incremento de los fondos disponibles para I+D+I en Asturias y del número de personas dedicado a estas actividades. El crecimiento de dichos fondos permitió duplicar el montante disponible (de 99.022.000€ en 2001 a 226.156.000€ en 2009) lo que se había reflejado en un aumento del personal empleado en el sector, que pasó de 2.175 trabajadores en 2003 a 3.768 en 2009. Este ascenso se truncó en 2009, año a partir del cual el sector se contrajo notablemente (30 millones de $€$ menos de 2009 a 2013, y 342 trabajadores menos),

Estos últimos años han demostrado la debilidad de las pequeñas empresas para acceder a los programas de $\mathrm{I}+\mathrm{D}+\mathrm{I}$. Hay un déficit de personal para labores de asesoramiento, ya sea en las estructuras administrativas habituales IDEPA, FICYT o 
agencias de desarrollo, y no hay mercado estable para consultoras de asesoramiento de I+D+I. De no colocar el foco en las PYMES facilitando su participación en programas y proyectos de investigación su implicación continuará disminuyendo. El futuro de la investigación e innovación se basará en la obtención de ayudas procedente de fondos europeos. El programa Horizonte 2020 de la Unión Europea, establece cambios importantes y crea un nuevo instrumento de ayudas, llamado “Instrumento PYME”, enfocado a las pequeñas empresas que quieran avanzar en un territorio y crecer a nivel global.

\subsection{El sector de las infraestructuras portuarias}

\subsubsection{Los puertos autonómicos}

Hay 24 puertos autonómicos en Asturias, son los de: Vegadeo, Castropol, Figueras, Tapia, Viavélez, Ortiguera, Navia, Puerto de Vega, Luarca, Oviñana, Cudillero, San esteban de Pravia, San Juan de la Arena, Avilés, Llumeres, Bañugues, Luanco Viejo, Luanco Nuevo, Candás, Tazones, El Puntal, Lastres, Ribadesella, Niembro , Llanes, Bustio. No todos cuentan con embarcaciones pesqueras matriculadas en ellos; los que si las registran son los 16 que aparecen en la Figura 25, en la que destaca Cudillero con el doble de embarcaciones que el siguiente, el de Luarca.

Figura 25 .Puertos autonómicos y embarcaciones pesqueras (2012)

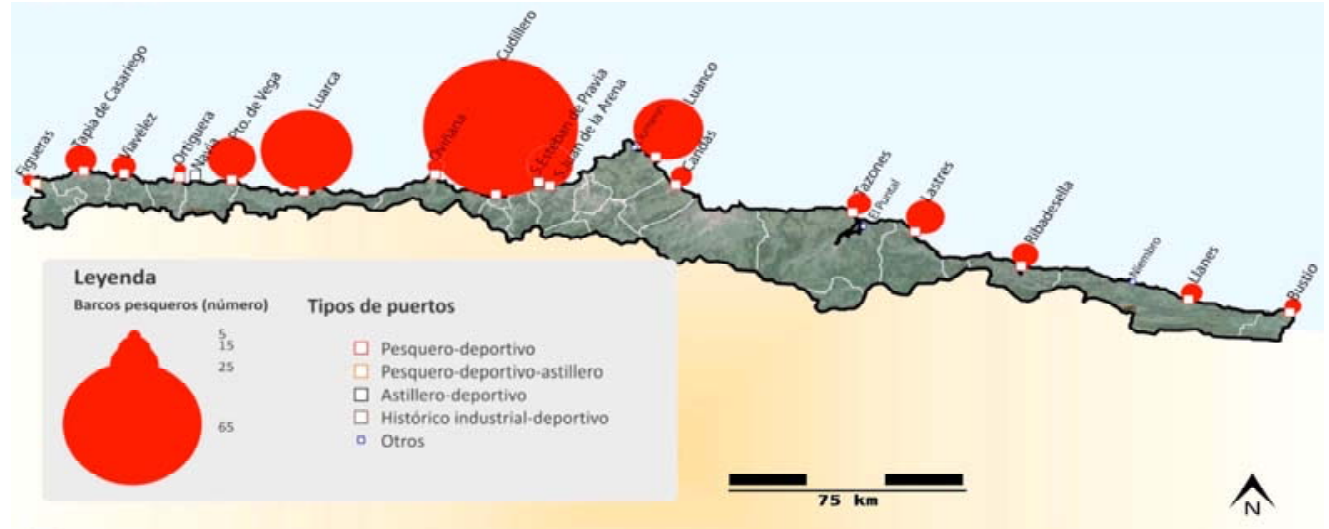

Fuente: www.magrama.es y www.sadei.es. Elaboración propia.

El puerto de Vegadeo, también denominado Castropol-Sur, está constituido por un muelle de atraque y una superficie de tierra donde se ubican varias naves, una con uso deportivo y otras pertenecientes al Astillero Gondán. El de Castropol no dispone de elementos de abrigo, solo de pantalanes de temporada, y ni uno ni otro cuentan con embarcaciones matriculadas, por lo que los hemos incluido en el contiguo de Figueras, los tres en el concejo de Castropol. El puerto de Navia concentra alrededor 
de su dársena las instalaciones del Astillero Armón, es un puerto industrial con pocas facilidades para los usuarios deportivos y sin embarcaciones pesqueras, con problemas de aterramiento en el canal de acceso, que necesita un constante dragado para dar viabilidad al astillero. El puerto de Llumeres, donde apenas se registra actividad náutica, es un elemento importante del patrimonio industrial asturiano, el dique donde se ubicaba el cargadero por el que salía el mineral de hierro de la explotación cercana presenta un importante deterioro. El puerto de Niembro, en la ría del mismo nombre, es apenas un pequeño muelle con una explanada de tierra contigua que acoge a embarcaciones de pequeño porte.

Figura 26. Clasificación de puertos autonómicos por número de embarcaciones pesqueras registradas (2011)

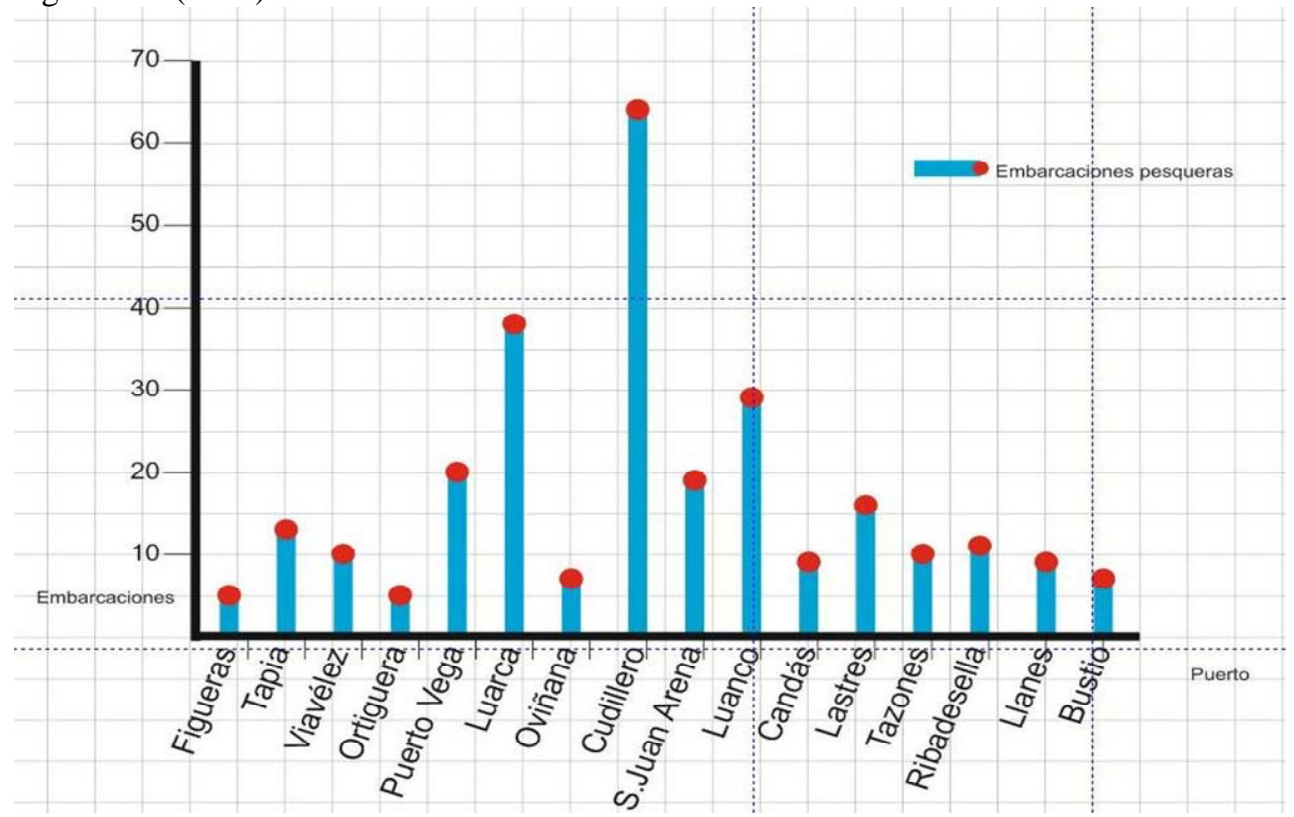

Fuente: www.magrama.es y www.sadei.es. Elaboración propia.

En la gran mayoría de ellos se están llevando a cabo obras de ampliación o de mejora (ampliación de pantalanes, dragado de los canales de entrada o salida, etc.). Los datos disponibles se refieren únicamente a la presencia de embarcaciones pesqueras en los puertos autonómicos, lo que ofrece un cuadro insuficiente por cuanto en muchos de los puertos estas embarcaciones comparten espacio con las deportivas. El número de embarcaciones pesqueras disminuye y la mayor parte se registran en el sector occidental, manteniéndose el centro y el oriente muy por debajo y casi a la par. Las tres áreas mantienen una línea descendente y paralela, que conoció un breve período de estabilidad entre 1995 y 1997, y que se compensa por la creciente presencia de embarcaciones de recreo. Una de las necesidades del subsector es la 
ordenación del sistema portuario autonómico, con el objeto de facilitar el desarrollo de las actividades productivas vinculadas a los puertos y ubicadas en su área de influencia. Es conveniente valorar las necesidades que estos artefactos tienen en cuanto a número de amarres, interconectividad entre puertos y gestión conjunta de lonjas, además de los requerimientos para la navegación segura en sus aguas restringidas, tales como el mantenimiento de los canales de entrada y salida y su adecuada señalización, además de asentar un marco institucional para las relaciones puerto-ciudad.

Figura 27. Embarcaciones pesqueras en puertos autonómicos por sectores de litoral (20012011)

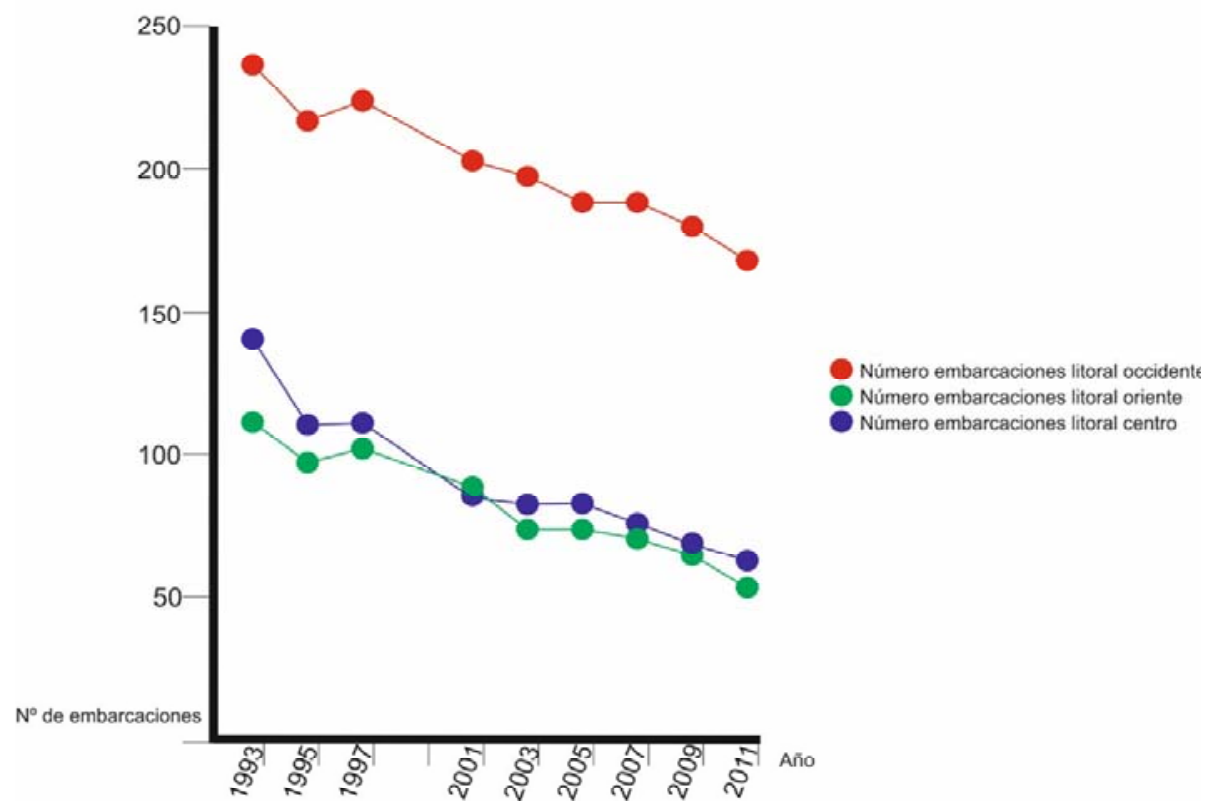

Fuente: www.magrama.es y www.sadei.es. Elaboración propia.

\subsubsection{Los puertos de interés general del Estado}

Asturias tiene dos puertos de interés general del Estado, el de Gijón y el de Avilés, gestionados por sus autoridades portuarias, dependientes del Ministerio de Fomento. 
Figura 28. Emplazamiento de los puertos del Estado en el litoral asturiano y tráfico de pasajeros y mercancías (2011)

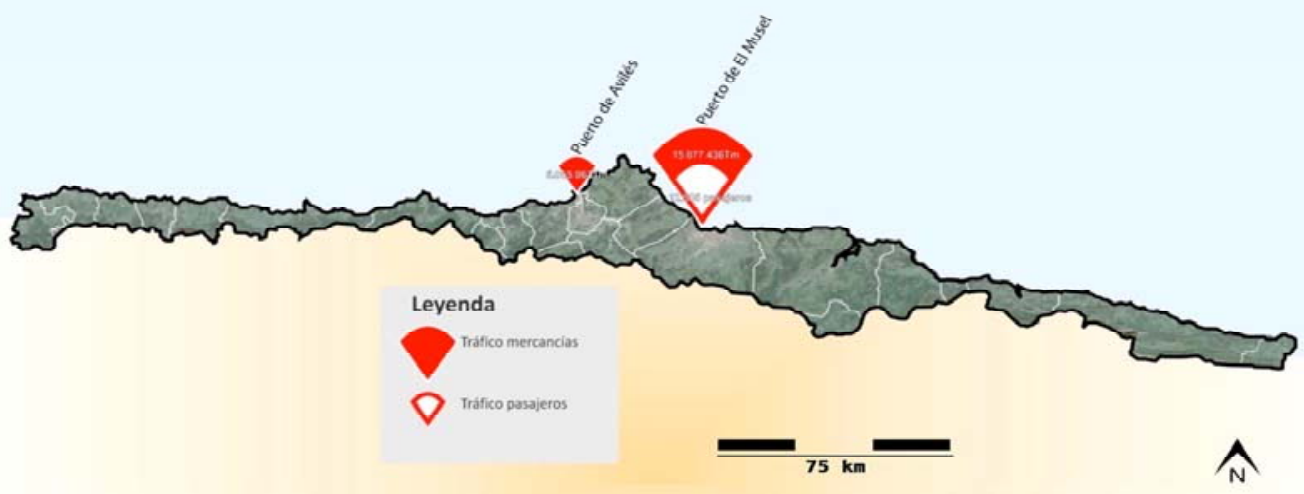

Fuente: www.puertos.es. Elaboración propia

Ambos tienen características y situaciones distintas. El de Avilés es un puerto de estuario integrado en la ciudad, lo que si por una parte condiciona su actividad, por otra le da un atractivo especial para el tráfico de pasajeros en buques de porte mediano. Basa su actividad en las empresas próximas, tales como Fertiberia, AZSA, Vestas, Gamesa, Mefasa, Química del Nalón, Chemastur, Aleastur, Alcoa, Asturfeito, Arcelor- Mittal, Dupont... que lo utilizan para importar materias primas, aunque en los últimos años el volumen de embarques se está incrementando. Elemento importante del puerto de Avilés es el muelle Oscar Niemeyer contiguo al Centro Cultural Internacional del mismo nombre, que permite atraques de buques cruceros y es un escenario de excelencia para nuevos desarrollos de la relación puerto-ciudad.

Figura 29. Tráfico de mercancías y pasajeros en los puertos de Avilés y Gijón (2011)

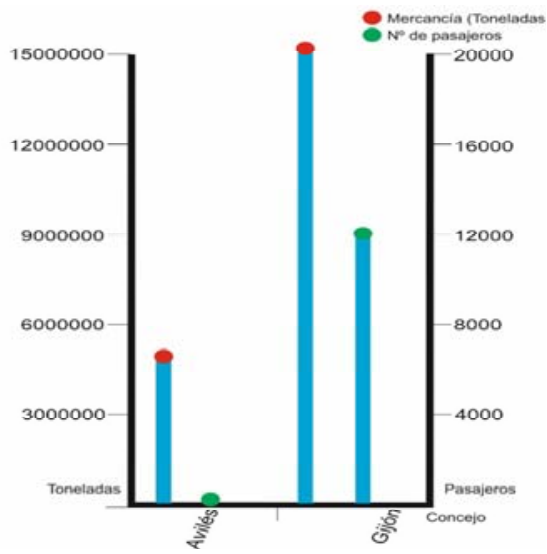

Fuente : www.puertos.es. Elaboración propia. 
El puerto de Gijón está anexo a la ciudad, ha experimentado importantes ampliaciones que han duplicado su tamaño y que lo capacitan para acoger a grandes buques. Debido a estas obras, el puerto tiene una carga financiera importante, por lo que su prioridad es encontrar grandes operadores mundiales para intensificar los tráficos y conseguir inversiones en las instalaciones de carga y descarga. Las obras recientes lo han singularizado, por calado, tamaño del canal de entrada, capacidad de atraque, superficie de almacenamiento....; sin embargo, los tráficos ligados a las empresas asentadas en la región no pueden mantenerlo por sí solos, por lo que es prioridad crítica del puerto expandir su "hinterland", lo que parece haber conseguido en 2013 con un incremento del 32\% en las toneladas manejadas respecto al año anterior

Hasta 2014 el puerto de Gijón dispuso de una Autopista del Mar que unía a Gijón con Nantes- Saint Nazaire, enfocada al transporte de vehículos de carga, turismos y pasajeros, fue apoyada financieramente por la Unión Europea y actualmente ha sido abandonada. La línea contribuyó al incremento del turismo de crucero que aumentó en un $40 \%$ con respecto a la situación previa. El puerto dispone de una planta regasificadora que no está operativa, a la espera de que un cambio tecnológico en el sector naval permita la utilización del gas como combustible para grandes buques,

La observación de la serie histórica de tráfico de mercancías en los puertos de Avilés y Gijón en los cincuenta últimos años, permite apreciar sensibles diferencias entre ellos, con una tendencia a la estabilidad en Avilés y una mayor irregularidad en Gijón. Partiendo de volúmenes de tráfico parecidos, Avilés estaba ligeramente por delante en 1965, posteriormente Gijón multiplicó por cinco el tráfico de mercancías, alcanzando sus cifras máximas a principio del presente siglo, para caer a partir de 2006.

Figura 30. Tráfico de mercancías en los puertos de Avilés y Gijón (1965-2011)

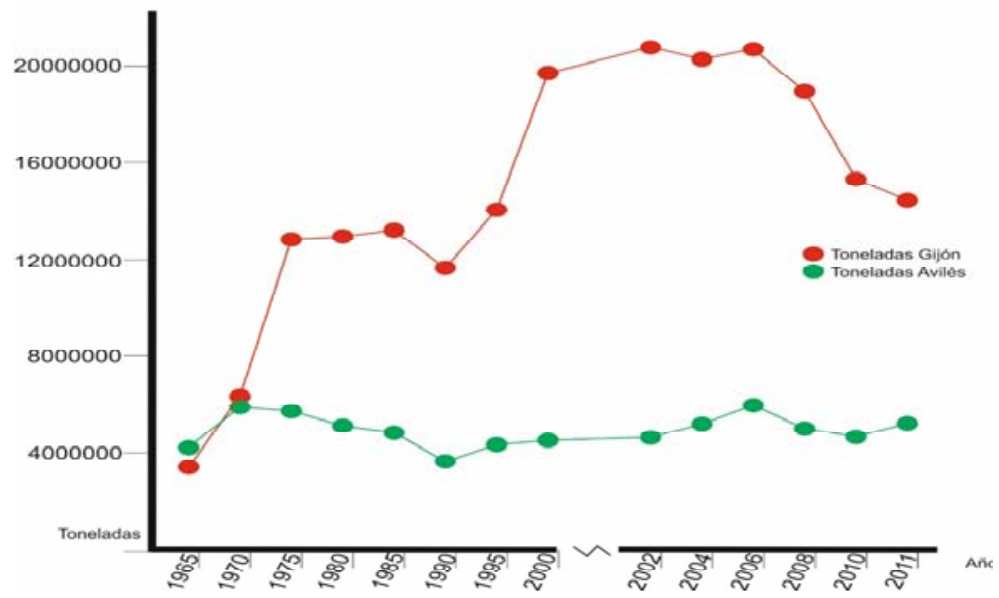

Fuente : www.puertos.es. Elaboración propia. 
El puerto de Avilés movió unos 4.000.000 de toneladas anuales, con un crecimiento moderado en el quinquenio 1965-1970, seguido de un descenso prolongado hasta tocar fondo en 1990; a partir de ahí se produce un aumento del tráfico, que durante los últimos años se ha mantenido por encima de los 5.000 .000 de toneladas anuales. El de Gijón parte de cifras ligeramente inferiores y también experimenta un crecimiento moderado hasta 1970. Aumenta el ritmo de crecimiento en los cinco años siguientes, en los que Avilés se estanca y Gijón se consolida como primer puerto regional. Durante los siguientes veinte años se mantuvo en cifras cercanas a las 13.000.000 de toneladas, y desde 1995 a 2000 supera las 20.000.000 toneladas anuales. En 2005 la tendencia se invierte y hoy ofrece valores situados entre los máximos de 2002 a 2006 y los de las dos últimas décadas del siglo pasado.

El puerto de Avilés tiene como reto principal la mejora de su conectividad con la red de carreteras de alta capacidad del Estado, ya que eso le permitiría extender su "hinterland" y con ello aumentar el volumen de gestión de tráficos. El ferrocarril, a través de líneas de ancho FEVE y RENFE, está presente en todos los muelles, sus limitaciones siguen siendo las generales de Asturias y las locales relacionadas con el trazado urbano. Aunque ya se ha comentado la limitación estructural que Avilés tiene para ampliar su espacio portuario, la que está en curso en la margen derecha es suficiente a medio plazo. El de Gijón, después de la ampliación realizada, que lo ha llevado a constituirse en uno de los puertos de referencia para el transporte de graneles sólidos en la fachada atlántica europea, con su terminal E.B.H.I en un muelle de 21 metros de calado en bajamar viva, tiene como prioridad crítica la de atraer operadores que generen tráficos y amplíen su "hinterland", pero se encuentra también con la difícil irradiación hacia el interior peninsular por ferrocarril; la variante ferroviaria de Pajares pondrá a la misma distancia los puertos de Gijón y Santander con Valladolid. Si bien Gijón tiene una buena conexión con las carreteras de gran capacidad del Estado, éstas introducen el tráfico en el interior de la ciudad, originando trastornos; se plantea dar accesos al puerto por una vía alternativa, ya solicitada al Ministerio de Fomento ofreciendo la cofinanciación al 50\%, pero dado el endeudamiento de la Autoridad Portuaria ésta pretende que el Ministerio de Fomento se haga cargo del $100 \%$ del coste de la obra, ligada a la conclusión de la Zona de Actividades Logísticas e Industriales de Asturias (ZALIA) común para los dos puertos. El de Avilés tiene previsto incorporar al espacio portuario dos canteras situadas en la margen derecha de la ría, pero aún no está determinado el fin de la concesión de su explotación. En San Juan de Nieva se tiene la intención de llevar a cabo un proyecto de diversificación de carácter turístico aún indefinido; en la actualidad se considera la posibilidad de habilitar un aparcamiento para caravanas, con el fin de dar servicio a la demanda de deportes náuticos como el surf. 


\section{El diagnóstico territorial por sectores económicos}

\subsection{El sector primario marino}

El sector primario marino está implantado a lo largo de todo el litoral de Asturias, aunque no de manera homogénea. Dentro de él, es la actividad pesquera la que ha contribuido a dibujar su funcionalidad y aspecto. Si bien hay una buena cobertura de la costa con puertos de origen y funcionalidad pesquera, su mayor concentración se da en el centro y occidente de la región, existiendo mayores distancias relativas entre los puertos orientales que, además, albergan menos actividad pesquera y más uso deportivo. Al oeste de Cudillero los puertos pesqueros se distribuyen regularmente, a razón de uno por municipio y, al contrario de lo que sucede en el sector oriental, la mayoría de ellos mantienen una flota pesquera relevante para el funcionamiento de sus sistemas locales. La actividad más alta se da en el área central , donde los puertos de Avilés y Cudillero, junto con Gijón, registran la mayor cantidad de embarcaciones pesqueras de Asturias. Avilés concentra gran parte de la pesca rulada, atrayendo a su mercado embarcaciones con base en los puertos circundantes y sacando provecho de las buenas comunicaciones y de la mayor especialización del Musel en el tráfico de mercancías.

Figura 31. Diagnóstico territorial integrado del sector primario marino

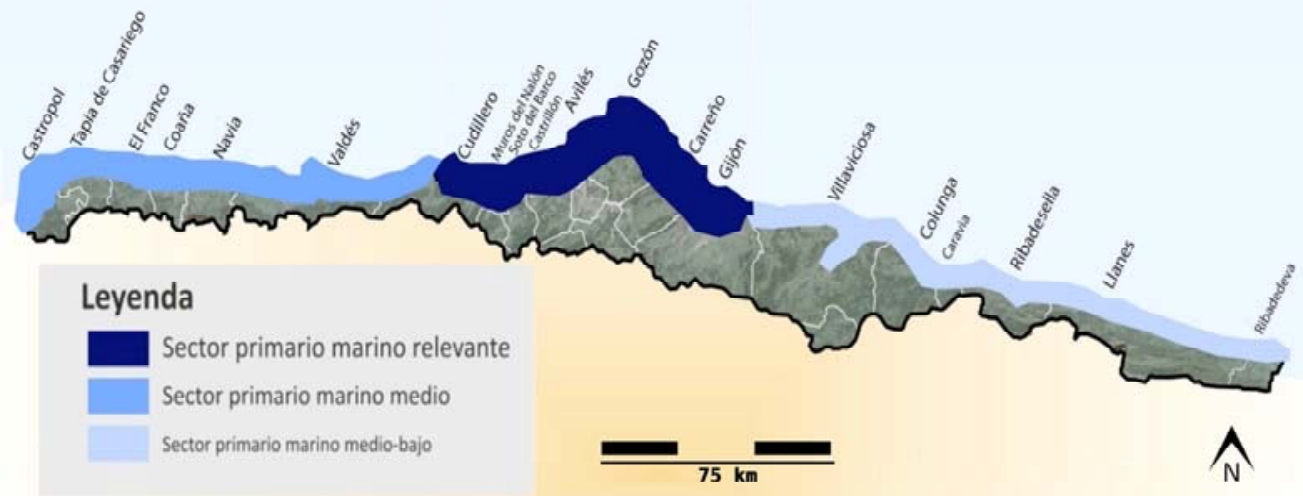

Fuente: Elaboración propia.

El marisqueo se distribuye uniformemente por toda la línea costera y la acuicultura se restringe a la ría del Eo.

\subsection{El sector primario terrestre}

La actividad ganadera está ligada a la producción de leche, se concentra en el sector occidental, concretamente a poniente del concejo de Valdés. En el centro de Asturias, con mayor presión urbanística y confluencia de actividades urbanas e industriales, hay una menor implantación del subsector ganadero, excepto en Gozón. A partir de 
Villaviciosa y hacia levante vuelve a registrarse más actividad ganadera, aunque sin alcanzar la implantación que se da en el occidente.

Figura 32. Diagnóstico territorial integrado del sector primario terrestre

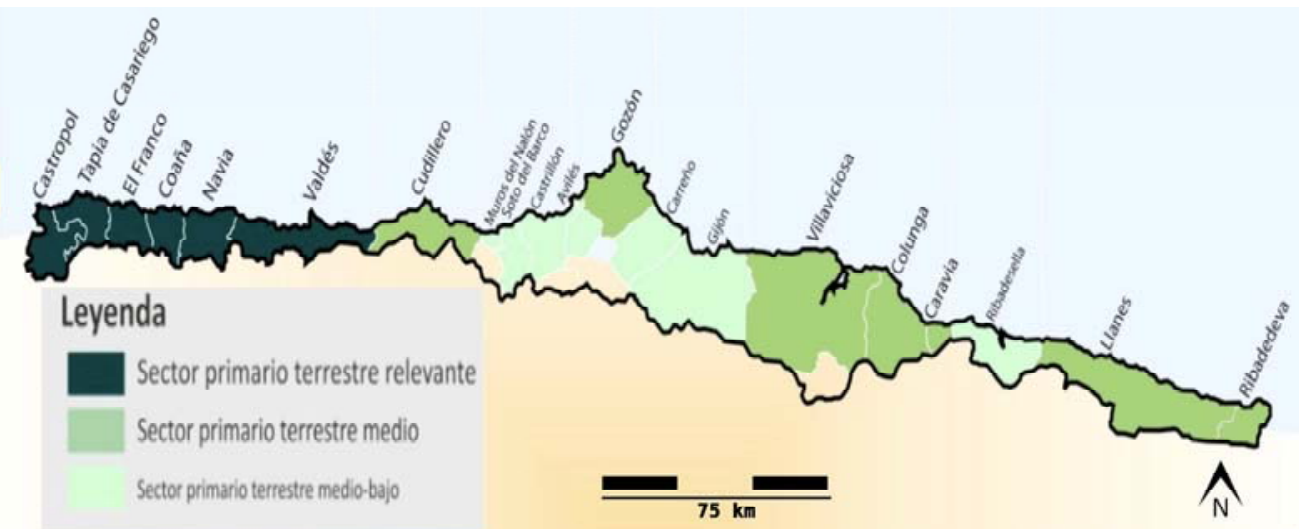

Fuente: Elaboración propia.

La mayor producción agrícola se da entre Valdés y Castropol. El sector oriental desde Caravia a Ribadedeva ha abandonado la agricultura, probablemente por la accidentada y seguramente por la presión turística y urbanística. Se erige un centro secundario de actividad agrícola litoral entre Gozón y Villaviciosa, y otro con producción apenas significativa entre Cudillero y Avilés.

Aunando ambos subsectores de actividad puede delimitarse un área con sector primario terrestre relevante entre Valdés y Castropol, dentro de la cual tanto la ganadería como la agricultura tienen una importante presencia. Al oriente de este área la distribución es desigual, con áreas de implantación media, donde domina una de las dos actividades o se dan valores intermedios en ambas (Cudillero, Gozón, Villaviciosa-Caravia, Llanes-Ribadedeva), y áreas de menor implantación, que coinciden con los municipios urbanos más importantes (Gijón y Avilés) y sus entornos.

\subsection{El sector industrial.}

Los astilleros se emplazan en el occidente (Figueras, Navia) y centro (Avilés, Gijón) de la región. En los últimos años importantes astilleros, como Naval Gijón, han desaparecido, pero tanto Armón como Gondán han conseguido mantener la actividad, consolidando a Navia, Gijón y Castropol como focos de producción, con Avilés como núcleo secundario. 
En Gijón y Avilés, así como en los concejos comprendidos entre ambos, se da una fuerte concentración de suelo industrial, ligada a la tradición metalúrgica de estos municipios y a su condición de cabeceras principales, junto con Oviedo, del área metropolitana asturiana, a la que aportan su especialización industrial, definiendo un área industrial en el eje Avilés-Gijón. El sector reduce su implantación en los concejos emplazados en las transiciones centro-franjas laterales, donde el suelo industrial tiene escasa implantación (es el caso de Villaviciosa, Colunga y Caravia, a un lado; y Castrillón, Soto de Barco, Muros y Cudillero, al otro). Hacia los sectores extremos las cifras de suelo industrial se incrementan, generándose cabeceras secundarias locales.

Figura 33. Diagnóstico territorial integrado del sector industrial

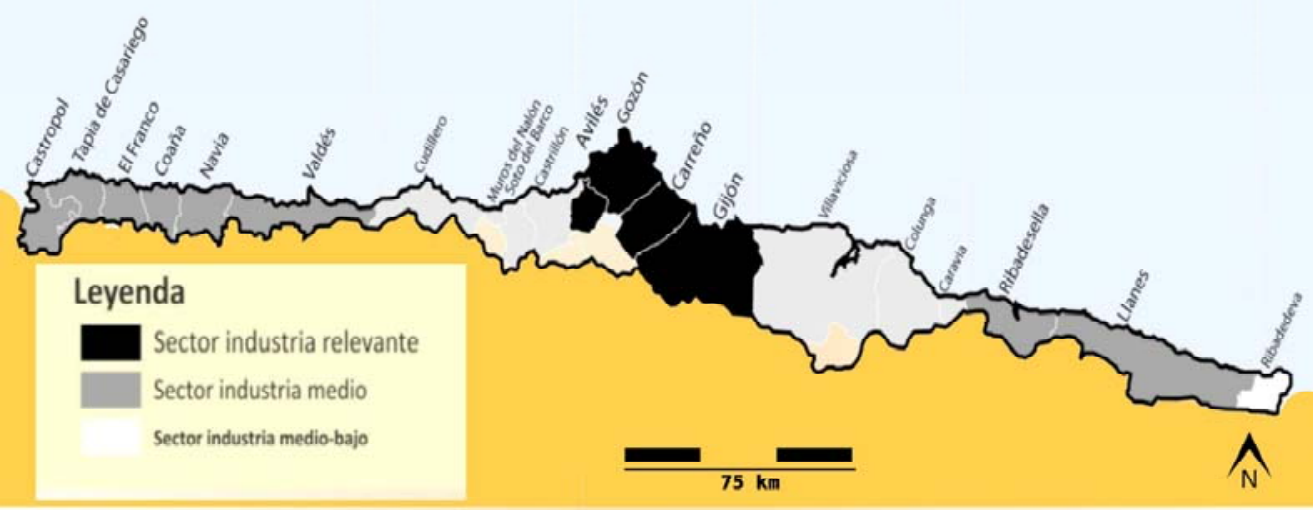

Fuente: Elaboración propia.

La conjugación de ambas variables delimita con claridad la presencia en el centro de Asturias de dos polos de concentración de la actividad industrial en Avilés y Gijón, unidos a través de Carreño y Gozón. La implantación del sector industrial es escasa en las transiciones hacia los extremos debido a la concentración que se produce en el centro; a partir de Ribadesella en el este y de Valdés en el oeste se dan áreas de implantación media, con una mayor especialización en occidente debido a la construcción naval y a la presencia de un polo industrial secundario en Navia-Coaña.

\subsection{El sector turístico}

El litoral oriental de Asturias registra la mayor actividad turística, siendo el concejo de Llanes el que concentra más plazas hoteleras. Concejos como Ribadedeva, Caravia o Colunga no ofrecen valores especialmente altos, quedando estos para las principales villas (Ribadesella y Villaviciosa, aparte de Llanes) y Gijón. 
Figura 34. Diagnóstico territorial integrado del sector turístico

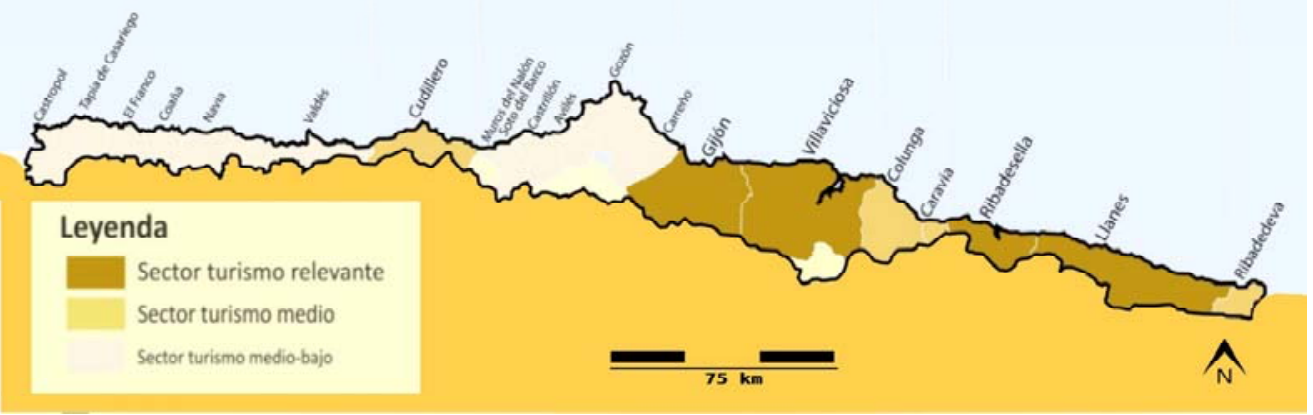

Fuente: Elaboración propia.

La impronta del sector turístico es desigual en la franja litoral. Se detecta un área de actividad relevante en Llanes y Ribadesella, pero que no encuentra continuidad hacia este y oeste, donde Gijón y Villaviciosa conforman el otro centro principal turístico. Al oeste de Gijón los valores son homogéneos y muy inferiores, excepto en Cudillero, con una implantación media, que se erige en cabecera de todo el occidente, aunque con valores inferiores a los del sector oriental.

\subsection{El sector de las infraestructuras portuarias}

Los veinticuatro puertos autonómicos dan servicio a la flota pesquera y a la deportiva. Todos tienen lista de espera para el amarre de embarcaciones y escasas plazas para el cabotaje. Hay al menos un puerto en cada uno de los concejos con fachada marítima, excepto en Caravia. La actividad dominante, dimensión e instalaciones de cada puerto refleja el tipo de relación que el territorio a que dan servicio tiene con la mar. De esta manera, hay instalaciones portuarias especializadas en la pesca, en usos recreativos, en el abastecimiento o la construcción de barcos.

Figura 35. Diagnóstico territorial integrado de las infraestructuras portuarias

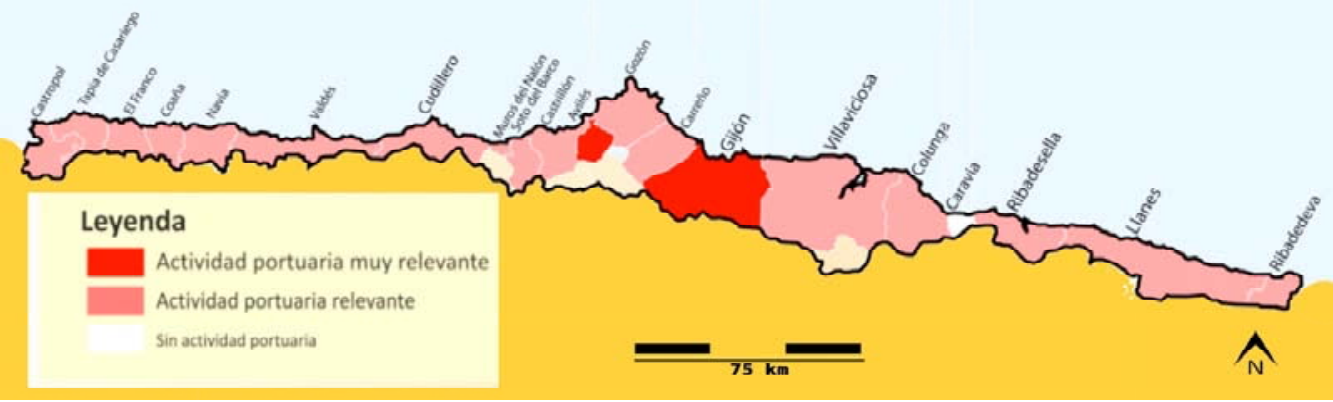

Fuente: Elaboración propia. 
Por la dimensión de sus infraestructuras, el volumen y diversidad de actividades que acogen, los puertos más importantes del litoral asturiano son en los de Avilés y Gijón. Este último es el de mayor volumen de tráfico de mercancías y pasajeros, así como de construcción de buques, $\mathrm{y}$, además, se confirma como uno de los más importantes de la fachada atlántica europea, en razón de la reciente ampliación de sus instalaciones y de su terminal de graneles sólidos (EBHI). Avilés, con menos capacidad de crecimiento debido a su situación, alberga una de las lonjas pesqueras de referencia en el Cantábrico, así como astilleros y actividad mercante, aunque de menor dimensión que el puerto de Gijón.

Los puertos autonómicos tejen una red tupida y diversa en torno de los dos anteriores, dando cobijo a la actividad pesquera, especialmente al oeste de Avilés, y recreativa-turística para sus entornos locales. La impronta tradicional es más patente hacia occidente, en puertos como Cudillero, Luarca o los pequeños de Ortiguera y Viavélez. Se sale de la norma el concejo de Navia, donde se emplazan dos infraestructuras complementarias: la de Puerto de Vega, especializada en la actividad pesquera, y la de Navia, que alberga amarres deportivos y astilleros en la desembocadura del río del mismo nombre. También Figueras alberga astilleros y, en el borde occidental del área metropolitana asturiana, el de San Esteban de Pravia, histórico puerto carbonero, alberga embarcaciones de uso recreativo entre un importante patrimonio histórico industrial.

\section{Conclusiones para detectar la ocupación dinámica del territorio}

Las cinco figuras anteriores representan los cierres de cada uno de los cinco sectores de actividad analizados. De la superposición de esos cinco mapas se obtiene la Figura 36 que representa el número de sectores que tienen presencia relevante en cada concejo. Se considera que a mayor presencia de los sectores de actividad en cada concejo, mayor capacidad funcional tendrá dicho concejo al acumular actividades y dinamismo, constituyéndose como espacio motor.

Figura 36. Espacios motores y de integración en el litoral asturiano

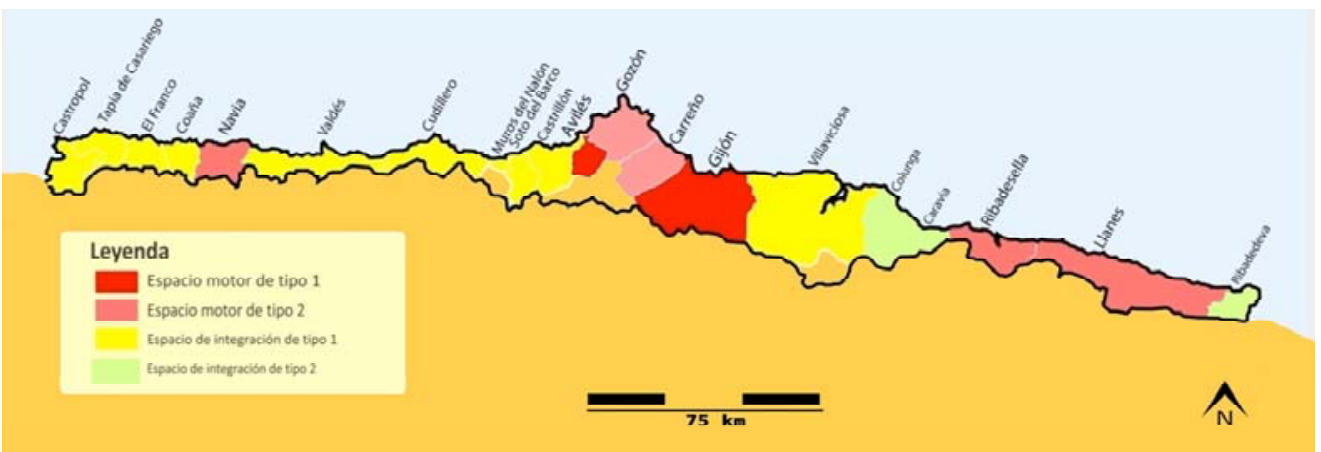

Fuente: Elaboración propia. 
Los concejos que tienen una presencia relevante de tres o más de los sectores analizados, se consideran "Espacios motores de tipo 1". Los que tienen presencia relevante de dos de los sectores analizados, se consideran "Espacios motores de tipo 2”. Los que tienen presencia relevante de uno de los sectores analizados, se consideran "Espacios de integración de tipo 1". Los que no tienen presencia relevante de ningún sector, se consideran “Espacios de integración de tipo 2”.

Los espacios motores acumulan actividad y dinamismo, presentando ventajas comparativas que los refuerzan y destacan dentro de la región. Los de tipo 1 son espacios caracterizados por su impronta metropolitana, generan un área de influencia que incluye a los concejos del entorno y se proyectan hacia otras escalas de orden superior, cuyo enlace efectivo necesita de la conexión a los vectores territoriales de estas redes internacionales. Los de tipo 2 se asocian con villas intermedias de alto potencial industrioso ya sea secundario o terciario y forman corredores longitudinales, dotados de una vida de carácter urbano propia y original, tanto en el sector oeste como en el este, rebasando a occidente los límites regionales para constituir una unidad con identidad propia, la marina asturlucense o Entrambasaguas, con alto potencial para constituir una nueva centralidad garante del equilibrio en la red policéntricas urbana de la cornisa cantábrica y estabilizadora del eje meridiano de la raya peninsular (Rodríguez, 2010)

Los espacios de integración están formados por concejos a incorporar a un desarrollo más equilibrado, en razón de las diferencias de potencial que presentan o de las debilidades que tienden a enclavarlos, dificultando su conectividad regional, lo que favorece su desvitalización social y su descapitalización física; si bien, su pertenencia a la unidad regional litoral es una característica determinante que contiene su evolución negativa, ofreciendo situaciones de integración de tipo 2 en enclaves localizados del sector oriental, relacionados con estrangulamientos físicos y con la divisoria regional. En este sentido las condiciones orográficas hacen aparecer un espacio llano que actúa como corredor favoreciendo la homogeneidad de toda la franja litoral.

El esquema refleja la concentración de actividad en el sector central, que contiene todos los sectores sobre dos polos urbanos: Gijón y Avilés, unidos en mancuerna por los de Gozón y Carreño, con lo que forman unidad de espacio motor, en el que la componente litoral debe ser relevante, pues los de Corvera e Illas situados contiguamente, pero en su ante-país interior y, por tanto, sin fachada costera, no presentan la misma relevancia. Desde esa cumbre, la tensión va decreciendo simétrica y paulatinamente hasta encontrar un cierto punto de ruptura, personalizado en los espacios de integración de tipo dos en el sector oriental (Colunga-Caravia) y Entrecabos (Vidio-Busto) en el occidental , que si bien no aparece reflejado en el mapa ello es debido a su enmascaramiento en los amplios concejos respectivos (Cudillero y Valdés), pues el grupo de parroquias de Entrecabos, de aparecer estadísticamente agrupadas, por ejemplo, como concejo, darían esta misma categoría, la de espacio de integración de tipo 2. El desarrollo longitudinal de las franjas laterales permite encontrar un espacio motor en cada una de ellas, dotados de una potencia de primer nivel que se concreta en Navía-Coaña para el sector occidental y 
Ribadesella-Llanes para el oriental. El extremo del área occidental, entre los ríos Navia y Eo (Entrambasaguas) se configura como un espacio de integración de tipo 1 con un potencial equilibrado, con relevancia del primario y del industrial y una trama urbana polinucleada y de intensa interacción que rebasa la ría del Eo, penetrando en $A$ Marinha lucense con la que parece formar unidad (Rodríguez, 2010)

La panorámica obtenida refleja una unidad litoral muy determinada físicamente y con un cierto equilibrio territorial, en la que la que hay un reparto regular de espacios motores y las situaciones críticas vienen a corresponderse con enclaves de pequeño tamaño que anticipan una realidad muy diferente a la litoral en el inmediato antepaís interior.

\section{Fuentes}

\section{$\underline{\text { Pesca tradicional }}$}

www.sadei .es

www.asturias.es/portal/site/medioambiente/

www.magrama.gob.es/es/estadistica/temas/estadisticas-pesqueras/pesca-maritima/

Acuicultura

www.asturias.es/portal/site/medioambiente/

www.magrama.gob.es/es/estadistica/temas/estadisticas-pesqueras/acuicultura/

Ganadería

www.asturias.es/portal/site/medioambiente/

www.magrama.gob.es/es/estadistica/temas/estadisticas-alimentacion/observatorioprecios/

www.sadei.es

$\underline{\text { Agricultura y silvicultura }}$

www.sadei.es

www.copaeastur.org

www.magrama.gob.es/es/alimentacion/temas/la-agriculturaecologica/documentos-deinteres/

Industria

www.gernaval.org

http://www.asturias.es/portal/site/medioambiente/

www.sadei.es

www.ine.es

www.faen.es

www.idepa.es

$\underline{\text { Turismo }}$

www.sita.org

www.ine.es

www.sadei.es

www.asturias.es/portal/site/medioambiente/ 
Investigación y desarrollo

www.ine.es

Puertos autonómicos

www.asturias.es/portal/site/medioambiente/

www.magrama.gob.es/es/estadistica/temas/estadisticas-pesqueras/pesca-maritima/

Puertos del Estado

www.puertos.es/estructura/distancia_puertos/

www.puertos.es/sistema_portuario/datos_economicos_inversiones/

www.puertos.es/estadisticas/estadistica_mensual/

www.puertos.es/estadisticas/estadistica_historica/

www.puertos.es/estadisticas/estadistica_desde_la_antiguedad/

www.puertos.es/estadisticas/anuarios_de_puertos/

Medio ambiente

www.puertos.es/oceanografia_y_meteorologia/redes_de_medida/

www.asturias.es/portal/site/medioambiente/

www.faen.es

Otros datos

http://www.asturias.es/portal/site/medioambiente/

www.sadei.es

www.ine.es

\section{Bibliografía}

Agardy, T., Davis, J., Sherwood, K., Vertergaard, O. (2011): “Taking steps toward marine and coastal ecosystem-based management, an introductory guide”, en UNEP. Regional seas reports and studies, núm.189.

CPRM y AAC (2006): Atlantic Spatial Development Perspective, Santa María da Feira, Portugal

Ferreira, M. y Fernández, P. (2014): Coastal \& Marine Union (EUCC). Position Paper for the Integration of Integrated Coastal Management (ICM) and Marine Spatial Planing (MSP) .EUCC-The Coastal Union

Gobierno del Principado de Asturias. Consejería de Medio Ambiente, Ordenación del Territorio e Infraestructuras (2005). Plan Territorial Especial de Ordenación del Litoral Asturiano (POLA). B.O.P.A. 197, de 25/08/2005.

Gobierno del Principado de Asturias. Consejeria de Fomento, Ordenacion del Teritorio y Medio Ambiente, Dirección General de Ordenacion del Teritorio y Urbanismo (2015). Plan Territorial Especial para la Estrategia Integrada para la Gestión Portuario-Litoral de Asturias (EIGPLA)

Nuñez, F.J. y Carrero, M.C. (2013): “Fragilidad”, en F.J. Nuñez, F. Rodríguez y R.M. Chavez.: Gestión integrada de paisajes litorales. Hacia una metodología comparativa. Caso Asturias, España, y Bahía Banderas, México. Plaza y Valdés, México D.F. pp.93-142. 
Pickaver, A. y Salman, A, (2006): “Integrated coastal management: Do we really have a choice?” Coastline vol. 15, núm 1/2, Special on Integrated Coastal Management. Luxembourg

Rodriguez, F., Moreno, C., Carrero, M. y Cuisinier, A. (coords.) (2006). Coastatlantic. Integrated Coastal Zone Management: towards an Atlantic Vision, Universidad de Oviedo.

Rodríguez, F. (2010): “El análisis del paisaje para la ordenación del territorio. Determinación de unidades de paisaje en la marina asturlucense”, en R. Rodríguez (dir) Territorio: Ordenar para competir. Netbiblo S.L., Oleiros, pp. 301-320 